\title{
Understanding Brønsted-Acid Catalyzed Monomolecular Reactions of Alkanes in Zeolite Pores by Combining Insights from Experiment and Theory
}

Jeroen Van der Mynsbrugge, ${ }^{1,3 \dagger}$ Amber Janda, ${ }^{1 \uparrow}$ Li-Chiang Lin,,${ }^{4}$ Veronique Van Speybroeck, ${ }^{3}$ Martin Head-Gordon, ${ }^{2}$ and Alexis T. Bell ${ }^{1 *}$

\author{
${ }^{1}$ Department of Chemical and Biomolecular Engineering \\ University of California, Berkeley, CA 94720, USA \\ ${ }^{2}$ Department of Chemistry \\ University of California, Berkeley, CA 94720, USA \\ ${ }^{3}$ Center for Molecular Modeling \\ Ghent University \\ Tech Lane Ghent Science Park Campus A, Technologiepark 903 \\ 9052 Zwijnaarde, Belgium \\ ${ }^{4}$ William G. Lowrie Department of Chemical and Biomolecular Engineering \\ The Ohio State University \\ $151 \mathrm{~W}$. Woodruff Ave. \\ Columbus, OH 43210, USA
}

\footnotetext{
* To whom correspondence should be addressed: alexbell@berkeley.edu

$\dagger$ J.V.d.M. and A.J. contributed equally to this work.

* Present address: Department of Chemical Engineering, Stanford University, Stanford, CA 94305, USA
} 


\section{Table of Contents Entry}

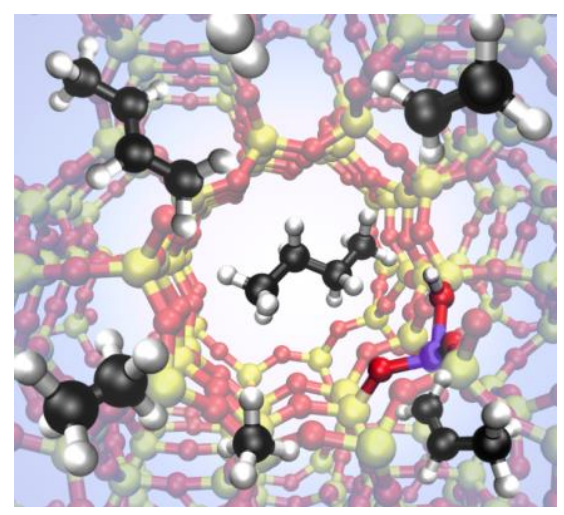

Acidic zeolites are widely used as catalysts to promote the cracking of high molecular weight hydrocarbons to lighter products required for gaseous and liquid fuels. Using monomolecular cracking and dehydrogenation of $\mathrm{C}_{3}-\mathrm{C}_{6}$ alkanes as an example, we review recent efforts combining experimental measurements and theoretical simulations to elucidate the influence of the zeolite structure on the catalytic activity at the Brønsted acid sites. 


\begin{abstract}
Acidic zeolites are effective catalysts for the cracking of large hydrocarbon molecules into lower molecular weight products required for transportation fuels. However, the ways in which the zeolite structure affects the catalytic activity at Brønsted protons are not fully understood. One way to characterize the influence of the zeolite structure on the catalysis is to study alkane cracking and dehydrogenation at very low conversion, conditions for which the kinetics are well defined. To understand the effects of zeolite structure on the measured rate coefficient $\left(\mathrm{k}_{\mathrm{app}}\right)$, it is necessary to identify the equilibrium constant for adsorption into the reactant state $\left(\mathrm{K}_{\mathrm{ads}-\mathrm{H}+}\right)$ and the intrinsic rate coefficient of the reaction $\left(\mathrm{k}_{\mathrm{int}}\right)$ at reaction temperatures, since $\mathrm{k}_{\mathrm{app}}$ is proportional to the products of $\mathrm{K}_{\mathrm{ads}-\mathrm{H}+}$ and $\mathrm{k}_{\text {int. }}$ We show that $\mathrm{K}_{\mathrm{ads}-\mathrm{H}+}$ cannot be calculated from experimental adsorption data collected near ambient temperature, but can, however, be estimated accurately from configurational-bias Monte Carlo (CBMC) simulations. Using monomolecular cracking and dehydrogenation of $\mathrm{C}_{3}-\mathrm{C}_{6}$ alkanes as an example, we review recent efforts aimed at elucidating the influence of the acid site location and the zeolite framework structure on the observed values of $\mathrm{k}_{\mathrm{app}}$ and its components, $\mathrm{K}_{\mathrm{ads}-\mathrm{H}+}$ and $\mathrm{k}_{\text {int. }}$
\end{abstract}

\title{
Keywords
}

zeolites, confinement, reactant state, adsorption, chemical kinetics, apparent rate parameters, intrinsic rate parameters, activation enthalpy, activation entropy, QM/MM, CBMC 


\section{Introduction}

Zeolites are crystalline microporous aluminosilicates that are widely used in the petroleum industry as catalysts to promote the cracking of high molecular weight compounds, principally alkanes, to lower molecular weight compounds required for gaseous and liquid fuels. ${ }^{[1-4]}$ The catalytically active sites in zeolites are Brønsted acidic protons that charge compensate anionic sites produced by the substitution of trivalent $\mathrm{Al}$ for tetravalent $\mathrm{Si}$ in the zeolite framework ( $\equiv \mathrm{Si}$ $(\mathrm{OH})-\mathrm{Al} \equiv)$. The activity of such sites depends on the acidity of the proton, which depends on the heteroatom (e.g., Al, Ti, B) ${ }^{[5]}$ but not the zeolite framework type ${ }^{[6,7]}$ or $\mathrm{Al}$ location, ${ }^{[5]}$ and on the spatial confinement ${ }^{[8-15]}$ of the proton. The latter property is defined by the size and shape of the pores and channels in the zeolite framework, which are similar in dimensions to those of reactants and products and reaction transition states. Spatial confinement is also responsible for the shapeselective properties of zeolites. ${ }^{[15,16]}$

Studies of alkane cracking have demonstrated that while cracking occurs mainly via a bimolecular mechanism at high conversion, a monomolecular pathway in which the alkanes are cracked or dehydrogenated by direct interaction with Brønsted acid protons prevails at very low conversions and low partial pressures (Figure 1). ${ }^{[17,18]}$ The latter mechanism has been shown to be first order in the alkane partial pressure, and the reaction rate in MFI (and by extension in equally or less confining frameworks) has been found to be unaffected by diffusional transport to the active sites for alkanes containing fewer than 10 carbon atoms and typical zeolite crystallite dimensions of 0.1-2 $\mu \mathrm{m} .{ }^{[19-21]}$ For these reasons, monomolecular cracking and dehydrogenation of alkanes are ideally suited for probing the influence of zeolite structure (pore size and topology) on the intrinsic activity and selectivity of Brønsted acid sites. 


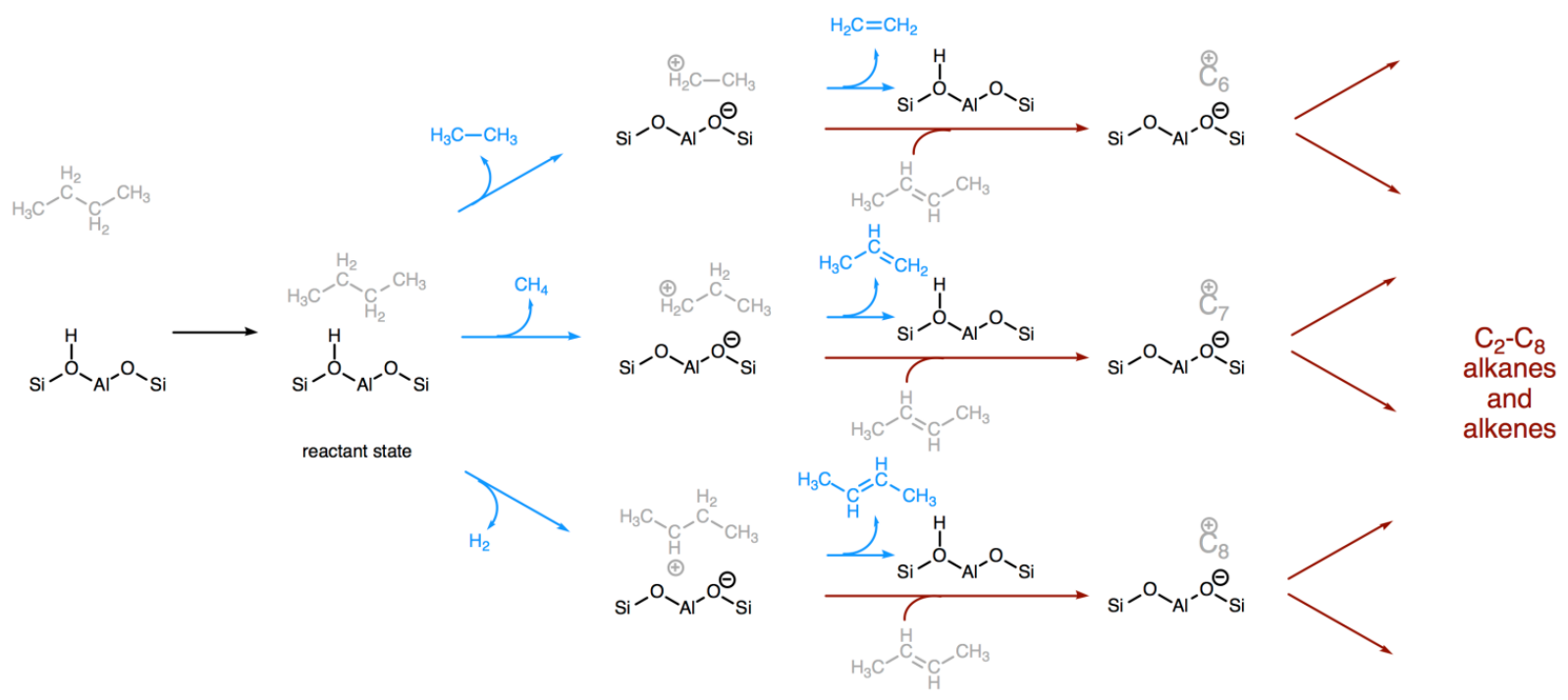

Figure 1. Reaction mechanisms for alkane cracking over Brønsted acid zeolites at low conversion (monomolecular reactions; blue) and high conversion (bimolecular reactions; red).

The mechanisms by which alkane cracking and dehydrogenation occur are shown in Figure 1. At low conversion, both reactions begin with adsorption of the alkane at a Brønsted acid site. Monomolecular cracking or dehydrogenation then occurs from this reactant state and, as illustrated, can lead to a variety of products via secondary reactions at higher conversion. Figure 2 illustrates the processes of alkane adsorption into the reactant state and the subsequent reaction in terms of the relevant changes in the enthalpy and entropy of the reactant relative to its presence in the gas phase. Since the concentration of alkane within the zeolite pores is small due to the weak interaction of the alkane with the Brønsted acid site and the low concentration of alkane within the zeolite pores, ${ }^{[8,22]}$ the occupancy of these sites $\left(\theta_{\mathrm{ads}-\mathrm{H}+}\right)$ can be described by Henry's law:

$$
\theta_{\text {ads- } \mathrm{H}+}=\mathrm{K}_{\mathrm{H}-\mathrm{H}+\mathrm{P}_{\mathrm{a}}}
$$


In eqn. $1, \mathrm{~K}_{\mathrm{H}-\mathrm{H}+}$ is the Henry's law constant for alkane adsorption to the reactant state, which is defined as any configuration in which an alkane $\mathrm{C}-\mathrm{C}$ bond is located within $5 \AA$ of an $\mathrm{Al} \mathrm{T}$-atom, ${ }^{[23]}$ and $\mathrm{P}_{\mathrm{a}}$ is the alkane partial pressure. The relationship of $\mathrm{K}_{\mathrm{H}-\mathrm{H}+}$ to the dimensionless thermodynamic equilibrium constant for adsorption to the reactant state, $\mathrm{K}_{\mathrm{ads}-\mathrm{H}+}$, is given by ${ }^{[24]}$

$$
\mathrm{K}_{\mathrm{H}-\mathrm{H}+} \equiv \frac{\mathrm{RT}}{\mathrm{V}_{\mathrm{H}+} \mathrm{n}_{\mathrm{H}}} \mathrm{K}_{\mathrm{ads}-\mathrm{H}^{+}}
$$

where $\mathrm{V}_{\mathrm{H}+}$ is the volume contained within one mole of reactant state spheres of radius $5 \AA$ and $\mathrm{n}_{\mathrm{H}+}$ is the moles of protons per unit mass of zeolite. Under such circumstances, the apparent rate coefficient $\left(\mathrm{k}_{\mathrm{app}}\right)$ of an elementary reaction depends on both the thermodynamics of the adsorption at the active sites $\left(\mathrm{K}_{\mathrm{ads}-\mathrm{H}+}\right)$ and the intrinsic rate coefficient $\left(\mathrm{k}_{\mathrm{int}}\right){ }^{[9,24]}$

$$
\mathrm{K}_{\mathrm{app}} \sim \mathrm{K}_{\mathrm{ads}-\mathrm{H}+\mathrm{K}_{\text {int }}}
$$

To improve overall performance, and select or design the optimal catalyst for a specific chemical transformation, it is important to understand how the environment enclosing the acid sites affects the enthalpy $(\Delta \mathrm{H})$ and entropy $(\Delta \mathrm{S})$ changes associated with the different steps illustrated in Figure 2. The effects of the environment on the kinetics can then be examined in terms of local variations among sites in different parts of a particular zeolite framework (e.g., channels vs. cages), or in terms of global variations among sites in entirely different frameworks (e.g., MFI vs. TON vs. MWW). In the former case, it is necessary to discern the location of the active sites in a given zeolite, while in the latter, it is important to base the comparison on rate data that are representative of all parts of the framework, i.e., with active sites located at a variety of crystallographic locations. In this Minireview we will review the literature on monomolecular cracking and dehydrogenation of alkanes in zeolites, and demonstrate how theoretical simulations can supplement experimental measurements to examine the influence of the location of Al atoms 
in a given zeolite framework and the effect of the overall framework structure on the values of $k_{\text {app }}$ and its components, $\mathrm{K}_{\mathrm{ads}-\mathrm{H}+}$ and $\mathrm{k}_{\text {int. }}$ This discussion will focus primarily on the monomolecular cracking and dehydrogenation of alkanes over H-MFI and other zeolites with similar pore sizes but differing in the size and prevalence of cages.

\section{ENTHALPY}

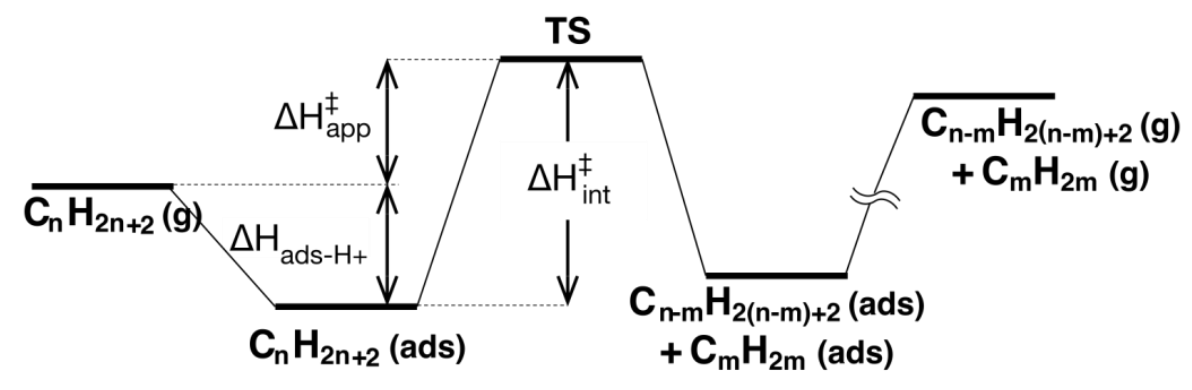

\section{ENTROPY}

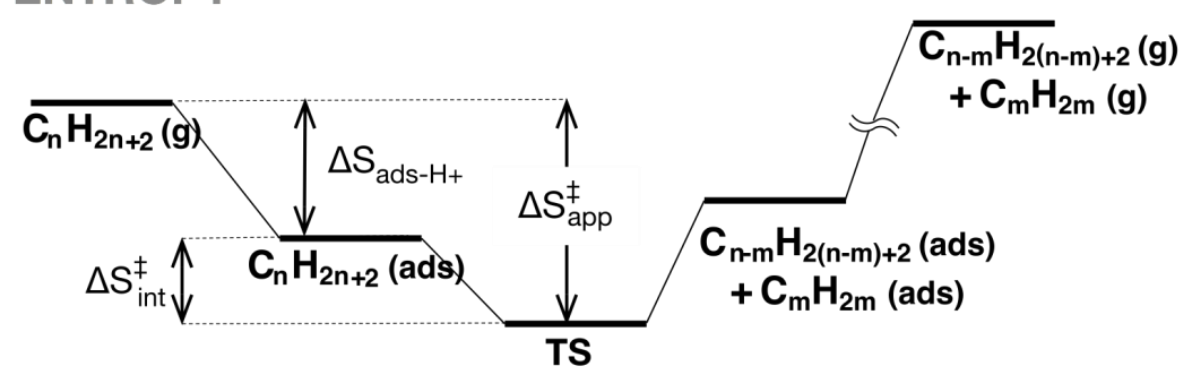

Figure 2. Schematic enthalpy and entropy landscapes illustrating the various steps in monomolecular reactions of alkanes in a Brønsted acid zeolite: the alkane adsorbs onto an active site, is converted into an alkene and a smaller alkane (cracking, $\mathrm{m}<\mathrm{n}$ ) or $\mathrm{H}_{2}$ (dehydrogenation, $\mathrm{m}=\mathrm{n}$ ), and the cracking or dehydrogenation products desorb from the active site. Apparent activation parameters $\left(\Delta \mathrm{H}^{*}\right.$ app and $\Delta \mathrm{S}_{\text {app }}^{\ddagger}$ ) extracted directly from experimental measurements are determined by both the adsorption enthalpy $\left(\Delta \mathrm{H}_{\text {ads-H+) }}\right.$ and adsorption entropy $\left(\Delta \mathrm{S}_{\mathrm{ads}-\mathrm{H}^{+}}\right)$of the reactants at the Brønsted acid sites and the intrinsic activation parameters $\left(\Delta \mathrm{H}^{\ddagger}{ }_{\text {int }}\right.$ and $\left.\Delta \mathrm{S}^{\ddagger}{ }_{\text {int }}\right)$ associated with the chemical transformation at the active site. 


\section{Experimental Studies of Reaction at Brønsted acid sites}

\subsection{Determination of activation parameters from experimentally measured rate coefficients}

To understand the influence of zeolite structure on cracking and dehydrogenation it is necessary to determine the enthalpy and entropy changes shown in Figure 2. To do so, experimental rate data are used to determine the apparent activation enthalpy and entropy $\left(\Delta \mathrm{H}^{*}\right.$ app and $\Delta \mathrm{S}^{\dagger}{ }_{\text {app }}$ ) from the temperature dependence of the measured first-order rate coefficients, $\mathrm{k}_{\text {app }}$, (e.g., an Arrhenius plot) for each reaction pathway. ${ }^{[8-12,22,24-26]}$ Values of $\Delta \mathrm{H}^{\ddagger}$ int and $\Delta \mathrm{S}_{\text {int }}^{\ddagger}$ can then be determined from eqns. 4 and 5, as follows:

$$
\begin{aligned}
& \Delta \mathrm{H}_{\text {app }}^{\dagger}=\Delta \mathrm{H}_{\text {ads-H+ }}+\Delta \mathrm{H}_{\text {int }}^{\dagger} \\
& \Delta \mathrm{S}_{\text {app }}^{\dagger}=\Delta S_{\text {ads-H+ }}+\Delta S_{\text {int }}^{\ddagger}
\end{aligned}
$$

It is evident from these equations that to determine $\Delta \mathrm{H}^{+}$int and $\Delta \mathrm{S}_{\text {int }}^{+}$at reaction temperatures $(>673$ $\mathrm{K})$ it is necessary to first determine $\Delta \mathrm{H}_{\mathrm{ads}-\mathrm{H}+}$ and $\Delta \mathrm{S}_{\mathrm{ads}-\mathrm{H}}$ at reaction temperatures. Until recently, ${ }^{\text {[27] }}$ this has not been attempted using experimental adsorption measurements because of the tendency of the alkane to relocate to siliceous parts of the framework at high temperature, and because of the occurrence of chemical reactions at temperatures above $\sim 600 \mathrm{~K} .{ }^{[28-30]}$ Moreover, several theoretical studies have shown that the distribution of adsorbed alkanes within the pores of a zeolite changes with the adsorption temperature, and consequently any insights gleaned from low temperature adsorption experiments are unlikely to be transferrable to reaction temperatures. ${ }^{[24,28-}$ 31] To overcome these concerns, Janda et al. have developed a theoretical approach based on configurational-bias Monte Carlo (CBMC) simulations using the Widom particle insertion method for determining the enthalpy $\left(\Delta \mathrm{H}_{\mathrm{ads}-\mathrm{H}^{+}}\right)$and entropy $\left(\Delta \mathrm{S}_{\mathrm{ads}-\mathrm{H}^{+}}\right)$changes for adsorption of gas phase

alkanes into reactant-state configurations at reaction temperature $(773 \mathrm{~K}) \cdot{ }^{[9,24,32]}$ These values of $\Delta \mathrm{H}_{\mathrm{ads}-\mathrm{H}+}$ and $\Delta \mathrm{S}_{\mathrm{ads}-\mathrm{H}+}$ can then be used to extract the intrinsic enthalpy and entropy of activation, 
$\Delta \mathrm{H}^{\dagger}{ }_{\text {int }}$ and $\Delta \mathrm{S}^{\dagger}{ }_{\text {int }}$, from the apparent enthalpy and entropy of activation, $\Delta \mathrm{H}^{\ddagger}$ app and $\Delta \mathrm{S}_{\text {app }}^{\ddagger}$, determined from experimental activation energies and rate coefficients. ${ }^{[9,24]}$

To determine $\Delta \mathrm{H}_{\text {ads-H+ }}$ and $\Delta \mathrm{S}_{\text {ads-H+ }}$, the reactant state is defined as the ensemble of configurations in which an alkane $\mathrm{C}-\mathrm{C}$ bond is located within $5 \AA$ of an $\mathrm{Al}$ T-atom. ${ }^{[23]}$ This distance is in line with the $\mathrm{Al}-\mathrm{C}$ distances obtained from DFT calculations for alkanes adsorbed at Brønsted sites in H-MFI and from molecular dynamics simulations for alkanes adsorbed in CHA reported in the literature. ${ }^{[24,28]}$ Values of $\Delta \mathrm{H}_{\mathrm{ads}-\mathrm{H}+}$ and $\Delta \mathrm{S}_{\text {ads-H+}}$ derived from CBMC simulations are in good agreement with those obtained from adsorption experiments at 300-400 $\mathrm{K}$, and at higher temperatures, the simulations also properly capture the tendency of alkanes to redistribute to less confining parts of the zeolite pore system (e.g, channels vs. cages). ${ }^{[24]}$ This redistribution affects the values of $\Delta \mathrm{H}_{\mathrm{ads}-\mathrm{H}^{+}}$and $\Delta \mathrm{S}_{\mathrm{ads}-\mathrm{H}^{+}}$as well as their variation with the chain length of the alkane, as discussed in Section 2.3.

\subsection{Effects of active site location}

Janda and Bell have investigated the rates and activation parameters of n-butane cracking and dehydrogenation for a series of commercial H-MFI samples with different $\mathrm{Si} / \mathrm{Al}$ ratios. ${ }^{[22]} \mathrm{As}$ discussed below, by sampling zeolites with a range of the $\mathrm{Si} / \mathrm{Al}$ ratio, a range of the $\mathrm{Al}$ distribution among crystallographically distinct T-sites is also effectively sampled, allowing characterization of the dependence of the kinetics on active site location. H-MFI exhibits twelve crystallographically distinct T-sites, which when occupied by Al can result in Brønsted acid sites that are located within the straight or sinusoidal channels, or at the channel intersections. ${ }^{[33]} \mathrm{By}$ extending the CBMC approaches developed by Swisher et al., ${ }^{[23]}$ Janda and Bell have found that the thermodynamics of n-butane adsorption in the reactant state vary among the different T-sites. 
Because the range of values observed for the apparent activation enthalpy and entropy $\left(\Delta \mathrm{H}^{\ddagger}\right.$ app and $\left.\Delta \mathrm{S}_{\text {app }}^{+}\right)$exceeded the range of values observed for the enthalpy and entropy of adsorption $\left(\Delta \mathrm{H}_{\text {ads- }}\right.$ $\mathrm{H}^{+}$and $\left.\Delta \mathrm{S}_{\mathrm{ads}-\mathrm{H}^{+}}\right)$amongst the $12 \mathrm{~T}$-sites, Janda and Bell inferred based on eqns. 4 and 5 that the intrinsic activation parameters for n-butane cracking and dehydrogenation must also vary depending on the location of the active site. ${ }^{[22]}$ This conclusion raises the question of how the distribution of $\mathrm{Al}$ atoms among $\mathrm{T}$-sites varies as a function of the $\mathrm{Si} / \mathrm{Al}$ ratio for zeolites of similar provenance.

While the exact crystallographic positions of the Al T-atoms and their charge-compensating protons in the zeolite framework cannot be determined experimentally, XRD,${ }^{[34,35]} \mathrm{UV}$-visible, ${ }^{[36-}$ ${ }^{40]}$ infrared, ${ }^{[41]}$ EXAFS,${ }^{[42]}$ and ${ }^{29} \mathrm{Si}^{[43-45]}$ and ${ }^{27} \mathrm{Al}^{[40,42,46-48]}$ MAS NMR spectroscopic techniques, together with theoretical work, have provided strong evidence that the distribution of $\mathrm{Al}$ is nonrandom and depends on the conditions of the synthesis. ${ }^{[49,50]}$ Although in most studies only the non-randomness of the $\mathrm{Al}$ distribution has been demonstrated, some authors have reported the distributions of protons amongst qualitatively different parts of the zeolite pore system. Bhan et al. ${ }^{[41]}$ have inferred the distribution of protons among the 8-ring side pockets and 12-ring main channels of H-MOR using in-situ IR spectroscopy of adsorbed alkanes. In addition, Dědeček et al. ${ }^{[36-40]}$ have inferred the locations of pairs of $\mathrm{Al}$ atoms (those close enough to compensate a divalent cation) within MFI using UV-Visible spectroscopy of Co(II)-exchanged MFI samples. By deconvolution of observed UV-Visible spectra, the authors have inferred the distributions of $\mathrm{Al}$ pairs among straight channels, sinusoidal channels and channel intersections, and demonstrated that the location of the $\mathrm{Al}$ pairs varies systematically with the $\mathrm{Si} / \mathrm{Al}$ ratio and synthesis conditions.

Using the same technique employed by Dědeček et al., ${ }^{[36-40]}$ Janda and Bell ${ }^{[22]}$ observed systematic trends in the distribution of Al pairs compensating the divalent $\mathrm{Co}(\mathrm{II})$ ions as a function 
of the $\mathrm{Al}$ content (Figure 3.a and 3.b) of commercial samples of MFI, all obtained from Zeolyst. As the number of $\mathrm{Al}$ atoms per unit cell increases, a larger fraction of Co(II) (and, thus, of Brønsted sites in the original sample) are located at the channel intersections relative to the more confining straight and sinusoidal channels. The spectroscopic technique developed by Dědeček et al. ${ }^{[36-40]}$ and applied by Janda and Bell ${ }^{[22]}$ cannot be used to infer the locations of isolated (i.e., non-paired) $\mathrm{Al}$ atoms. However, as noted in ref ${ }^{[22]}$, the distributions of isolated and paired $\mathrm{Al}$ sites would have to be strongly anti-correlated in order for the distribution of Al pairs to not reflect qualitatively the distribution of isolated $\mathrm{Al}$ atoms, and of $\mathrm{Al}$ atoms in general, among the different pore environments.

The increase in the fraction of Al pairs located at intersections discussed above was found to coincide with a general increase in the apparent activation parameters $\left(\Delta \mathrm{H}^{\ddagger}\right.$ app and $\left.\Delta \mathrm{S}_{\text {app }}^{\dagger}\right)$, in the turnover frequencies for both cracking and dehydrogenation (Figure 3.c), and in the selectivity for dehydrogenation vs. cracking as well as for terminal cracking vs. central cracking (Figure 3.d). ${ }^{[22]}$ From these observations and the above-mentioned CBMC-calculated variation in adsorption thermodynamics among the 12 T-sites, Janda and Bell proposed (using eqns. 4 and 5) that the changes in the apparent activation parameters $\left(\Delta \mathrm{H}^{\ddagger}\right.$ app and $\Delta \mathrm{S}^{\ddagger}$ app $)$ are at least partly driven by underlying changes in the intrinsic activation parameters $\left(\Delta \mathrm{H}^{\ddagger}\right.$ int and $\Delta \mathrm{S}^{\ddagger}$ int) with changes in the confinement of Brønsted protons. Consistent with this proposal, in more recent work Bučko and Hafner have found, using molecular dynamics simulations, that $\Delta \mathrm{S}^{\dagger}$ int for propane cracking differs significantly between the 12-ring channels and 8-ring side pockets of H-MOR. ${ }^{[29]}$

As discussed in ref ${ }^{[9]}$, the conclusion of Janda and Bell ${ }^{[22]}$ that confinement influences the apparent activation parameters $\left(\Delta \mathrm{H}^{\ddagger}\right.$ app and $\Delta \mathrm{S}^{\ddagger}$ app $)$ of alkane cracking and dehydrogenation has been reported in a number of previous studies. However, the conclusion of Janda and Bell that 
confinement also influences the intrinsic activation parameters $\left(\Delta \mathrm{H}^{\ddagger}\right.$ int and $\left.\Delta \mathrm{S}_{\text {int }}^{\ddagger}\right)$ contrasts with the previous conclusions, as discussed below, that the intrinsic activation enthalpy $\left(\Delta \mathrm{H}^{\ddagger} \text { int }\right)^{[8,10 \text { - }}$ 12,25,26] and entropy $\left(\Delta \mathrm{S}_{\text {int }}^{\dagger}\right)^{[10,12,13]}$ are independent of the Brønsted acid site confinement. The reasons given by Janda and Bell for the observed increase in the activation parameters as the fraction of sites located at intersections vs. channels increases were connected to differences in transition-state geometries, discussed further in Sections 2.4 and 3 and calculated using density functional theory. The results of the DFT calculations demonstrate that cracking transition states occur earlier along the reaction coordinate relative to dehydrogenation transition states, ${ }^{[51]}$ which Janda and Bell suggest causes the intrinsic free energy barrier $\Delta \mathrm{G}^{\ddagger}$ int for dehydrogenation transition states to be lowered in less confining pore spaces relative to those for cracking transition states.

(a)

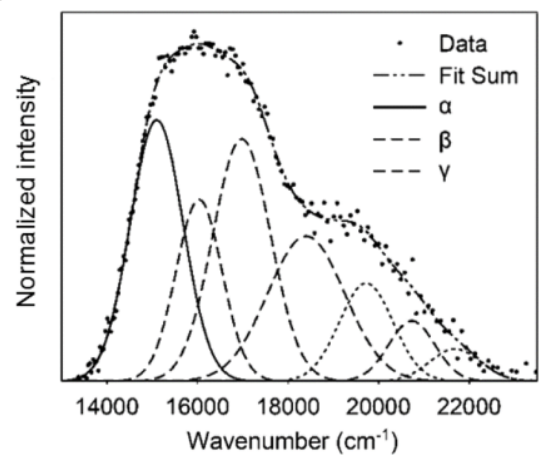

(c)

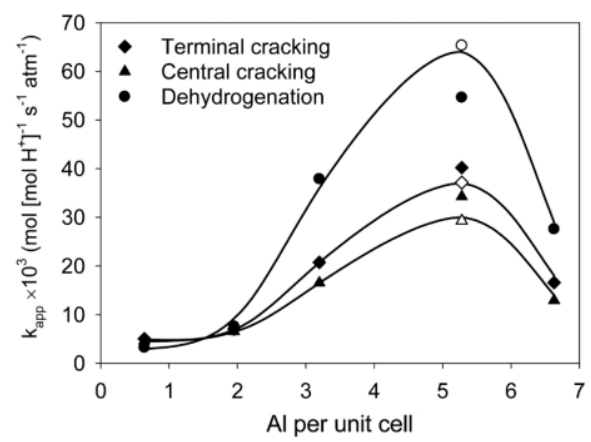

(b)

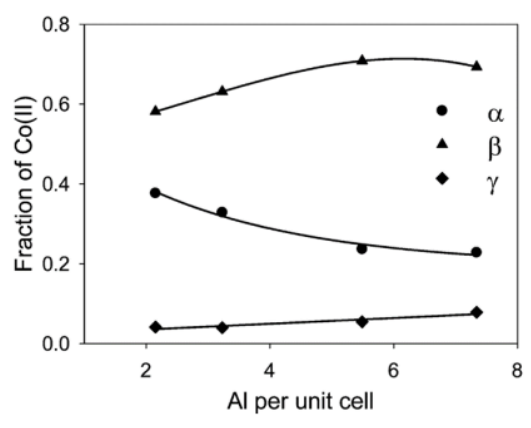

(d)

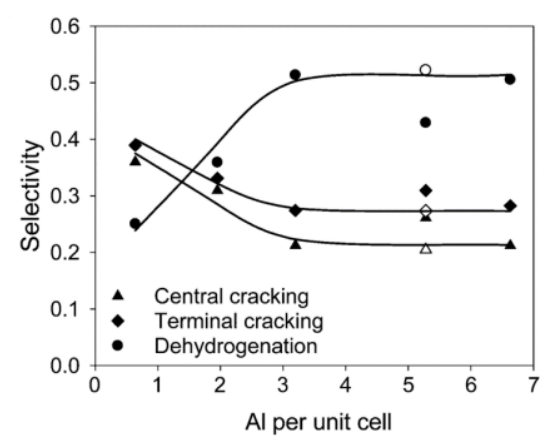


Figure 3. (a) Experimental UV-visible spectrum for a (Co,Na)-MFI sample, numerically smoothed for ease of visualization. (b) Plot of the distribution of $\mathrm{Co}$ (II) among straight and sinusoidal channels and intersections as a function of $\mathrm{Al}$ atoms per unit cell in H-MFI. (c) First-order rate coefficients of monomolecular cracking and dehydrogenation of n-butane as a function of Al atoms per unit cell in H-MFI. (d) Selectivities for monomolecular n-butane reactions as a function of Al atoms per unit cell in H-MFI. Data for MFI-15(M), which was treated with EDTA, are indicated with hollow symbols. Adapted from ref. [22]

The observations of Janda and Bell ${ }^{[22]}$ contrast with earlier reports by Haag and Dessau, who found no systematic variation of the activity per Al atom for the overall rate of consumption of $\mathrm{n}$-hexane in $\mathrm{H}-\mathrm{MFI}$ over a wide range of $\mathrm{Si} / \mathrm{Al}$ ratios. ${ }^{[52-54]}$ This difference may be a consequence of a constant $\mathrm{Al}$ distribution in the zeolite samples used by Haag and Dessau resulting from differences in the synthesis procedure used to prepare the zeolite samples used by the two sets of authors. As mentioned above, a number of previous studies, ${ }^{[36-50]}$ have demonstrated that the zeolite synthesis method strongly affects the distribution of $\mathrm{Al}$ atoms within various zeolites. Gounder and Iglesia have also reported variations in both the rate coefficients and selectivities of monomolecular reactions of propane over commercial $\mathrm{H}-\mathrm{MFI}$ samples differing in the $\mathrm{Si} / \mathrm{Al}$ ratio. ${ }^{[8]}$ Although these authors did not observe any systematic trends in catalytic behavior over the narrower range of $\mathrm{Al}$ content investigated, the observed differences suggest that differences in Al siting and possibly underlying differences in intrinsic kinetics may influence the differences in kinetics among the H-MFI samples.

Rather than investigate the distribution of $\mathrm{Al}$ within $\mathrm{H}-\mathrm{MFI}$ as a function of $\mathrm{Si} / \mathrm{Al}$ ratio, as was done by Janda and Bell, ${ }^{[22]}$ Gounder and Iglesia ${ }^{[8]}$ characterized the distribution of protons among the 8-ring side pockets and 12-ring main channels of H-MOR by deconvolution of the infrared bands corresponding to the $\mathrm{OH}$ stretching vibrations of protons in each location. ${ }^{[41]}$ Using this information, they were able to calculate the rates and selectivities of dehydrogenation and cracking of propane and n-butane for each of these environments in H-MOR. Gounder and Iglesia 
attributed differences in the rates and selectivities among the 8-ring side pockets and 12-ring channels to differences in activation entropy and to the relative stabilities of different transition states (referenced to the gas phase) corresponding to each reaction pathway within these environments. ${ }^{[8]}$ Specifically, they concluded, similar to Janda and Bell, ${ }^{[22]}$ that later transition states such as dehydrogenation are preferred at less confining locations such as the 8-ring side pockets vs the 12-ring channels. Gounder and Iglesia ${ }^{[8]}$ also used previously reported adsorption data obtained at room temperature to infer that the intrinsic activation energies for the two pore environments are the same within error and that $k_{a p p}$ is dominated by the influence of the entropy of the transition state relative to its presence in the gas phase. Unlike Janda and Bell ${ }^{[22]}$ Gounder and Iglesia ${ }^{[8]}$ did not implicate differences in intrinsic activation parameters in explaining differences in kinetics among the 8-ring side pockets and 12-ring channels, and intrinsic activation parameters were implicitly (for $\Delta \mathrm{S}^{\dagger}$ int) or explicitly (for $\Delta \mathrm{H}^{\dagger}$ int) concluded to be the same for the two locations.

We suggest that there are two possible reasons for this discrepancy. The first is related to the method of calculation employed by Gounder and Iglesia ${ }^{[8]}$ to determine intrinsic activation parameters. The value of $\Delta \mathrm{H}^{\dagger}$ int was determined by these authors using eqn. 4 together with adsorption data measured at room temperature for the 8-ring side pockets and 12-ring channel locations using geometrical arguments. It is possible that, as a result of the uncertainty introduced by this method of estimation, to a first approximation the values of $\Delta \mathrm{H}^{*}$ int appeared to be within experimental error for the two environments.

A second possible reason for the different conclusions of Gounder and Iglesia ${ }^{[8]}$ vs. Janda and Bell[ ${ }^{[22]}$ is that the range of confinements represented by the 8-ring side pockets and 12-ring main channels of MOR are small enough such that differences in $\Delta \mathrm{H}^{\ddagger}$ int and $\Delta \mathrm{S}^{\ddagger}$ int among the two 
locations are insignificant. Consistent with the conclusions of Gounder and Iglesia, in our recent work $^{[9]}$ (cf. Section 2.4) we found that differences in the values of $\Delta \mathrm{H}^{\dagger}$ int and $\Delta \mathrm{S}^{\dagger}{ }_{\text {int }}$ among zeolite structures having similar levels of average confinement are within experimental error. However, as discussed in section 2.4, when zeolite structures having a wide range of the confinement of Brønsted protons is sampled, and accurate values of $\Delta \mathrm{H}_{\text {ads- } \mathrm{H}_{+}}$and $\Delta \mathrm{S}_{\mathrm{ads}-\mathrm{H}+}$ calculated using CBMC simulations at reaction temperature are used to determine $\Delta \mathrm{H}^{\ddagger}$ int and $\Delta \mathrm{S}^{\ddagger}$ int, trends in $\Delta \mathrm{H}^{\ddagger}$ int and $\Delta \mathrm{S}^{\ddagger}$ int with respect to confinement become apparent.
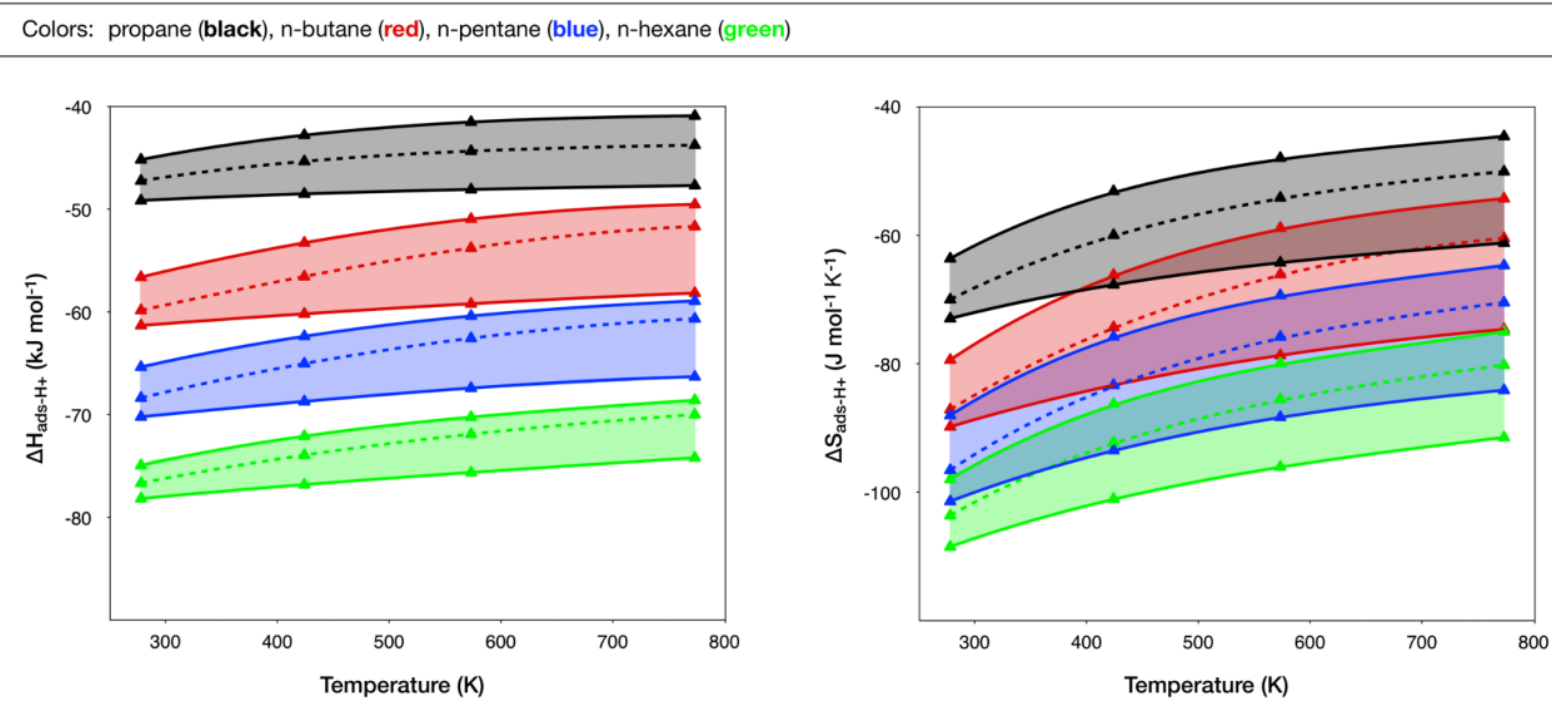

Figure 4. Plots of (a) enthalpy changes $\Delta \mathrm{H}_{\text {ads- } \mathrm{H}^{+}}$and (b) entropy changes $\Delta \mathrm{S}_{\text {ads-H+ }}$ for the adsorption of propane (black triangles), n-butane (red triangles), n-pentane (blue triangles) and and n-hexane (green triangles) from the gas phase onto Brønsted protons in H-MFI with one Al per unit cell obtained using CBMC simulations. The upper and lower solid lines correspond to Al located only at T9 and T4, respectively. The dashed lines represent the Boltzmann weighted averages of $\Delta \mathrm{H}_{\mathrm{ads}-\mathrm{H}^{+}}$and $\Delta \mathrm{S}_{\mathrm{ads}-\mathrm{H}^{+}}$for $\mathrm{Al}$ distributed evenly between T9 and T4. Adapted from ref. ${ }^{[24]}$.

\subsection{Effects of alkane chain length}

Janda et al. ${ }^{[24]}$ have also investigated the effects of the chain length of n-alkanes on cracking kinetics within H-MFI using a combination of previously reported experimental apparent 
activation energies and rate coefficients ${ }^{[55]}$ to calculate the intrinsic activation parameters for propane through n-hexane. Independent QM/MM calculations were also performed for the T-12 site of MFI, located at the intersection of the straight and sinusoidal channels. To extract intrinsic activation parameters from experimental data, the authors developed and employed a two-step CBMC approach to calculate enthalpies and entropies of adsorption of n-alkanes from the gas phase to the reactant state at reaction temperature $(773 \mathrm{~K})$. They then used these values together with eqns. 4 and 5 to determine the intrinsic activation parameters for the overall consumption of each alkane, normalized by the number of $\mathrm{C}-\mathrm{C}$ bonds. ${ }^{[24]}$ The advantage of the CBMC simulations is that they properly account for the changes in the distribution of alkane amongst different environments in the zeolite at high temperature and they also account for the greater number of configurations explored by the alkane in the vicinity of the active site at high temperatures. ${ }^{[24,28-31]}$

Figure 4 shows the CBMC-calculated values of $\Delta \mathrm{H}_{\text {ads-H+ }}$ and $\Delta \mathrm{S}_{\text {ads-H+ }}$ as a function of temperature for the adsorption of propane, n-butane, n-pentane and n-hexane in H-MFI. ${ }^{[24]}$ The solid curves represent the results of $\mathrm{CBMC}$ simulations in which the $\mathrm{Al}$ atom is placed at either the T9 (upper solid curves) or the T4 (lower solid curves) site in the MFI unit cell, and represent those sites for which the magnitudes of $\Delta \mathrm{H}_{\mathrm{ads}-\mathrm{H}^{+}}$and $\Delta \mathrm{S}_{\mathrm{ads}-\mathrm{H}^{+}}$are the smallest (for T9, located at the channel intersection) and the largest (for T4, located in the sinusoidal channel). The dotted curves, which represent the Boltzmann averaged values of $\Delta \mathrm{H}_{\text {ads- }-\mathrm{H}^{+}}$and $\Delta \mathrm{S}_{\text {ads- }} \mathrm{H}^{+}$for a zeolite in which the $\mathrm{Al}$ is evenly distributed between the two sites, indicate that alkanes adsorb primarily in the channels at ambient temperature, and redistribute towards the more spacious intersections at higher temperatures. For n-butane, the relative probability of the alkane adsorbing at T9 vs T4 changes smoothly by a factor of $\sim 6$ in moving from 275 to $773 \mathrm{~K} \cdot{ }^{[24]}$ Additionally, the dependences of $\Delta \mathrm{H}_{\mathrm{ads}-\mathrm{H}^{+}}$and $\Delta \mathrm{S}_{\mathrm{ads}-\mathrm{H}^{+}}$on alkane chain length are expected to be weaker for intersections vs. 
channels. This proposal is based on the observation of Eder and Lercher ${ }^{[56]}$ that the slope of a plot of $\Delta \mathrm{S}_{\mathrm{ads}-\mathrm{H}+}$ and $\Delta \mathrm{H}_{\mathrm{ads}-\mathrm{H}+}$ is larger for more confining zeolite structures. As a result, the dependence on chain length of $\Delta \mathrm{H}^{\ddagger}$ int and $\Delta \mathrm{S}^{\dagger}$ int extracted from eqns. 4 and 5 using $\Delta \mathrm{H}_{\text {ads- } \mathrm{H}_{+}}$and $\Delta \mathrm{S}_{\text {ads-H+}}$ determined at $773 \mathrm{~K}$ is expected to differ from that found using experimental adsorption data measured at $300-400 \mathrm{~K}^{[57]}$

The relocation of the adsorbed alkane to less confining spaces at high temperature and the consequences for $\Delta \mathrm{H}_{\mathrm{ads}-\mathrm{H}+}$ and $\Delta \mathrm{S}_{\mathrm{ads}-\mathrm{H}+}$ are expected to be even more pronounced in materials with more heterogeneous pore systems. ${ }^{[2]}$ As an example, Figure 5 shows the distribution of n-butane at $50 \mathrm{~K}$ and $773 \mathrm{~K}$ in the zeolite $\mathrm{H}-\mathrm{MWW}$, which consists of sinusoidal channels and super cages. ${ }^{[31]}$ At $50 \mathrm{~K}$, the alkane is localized to the most confining part of the zeolite in the vicinity of the acid site, while at reaction temperatures $(773 \mathrm{~K})$, the alkane explores a larger volume as it moves into the 12-ring supercages. Classical extrapolation of values of $\Delta \mathrm{H}_{\text {ads- }}+\mathrm{H}^{+}$and $\Delta \mathrm{S}_{\mathrm{ads}-\mathrm{H}+}$ to temperatures of cracking, or treating these values as temperature-invariant, does not properly account for such temperature-dependent changes in the siting of the alkane and in the concomitant change in the dependence of $\Delta \mathrm{H}_{\mathrm{ads}-\mathrm{H}^{+}}$and $\Delta \mathrm{S}_{\mathrm{ads}-\mathrm{H}^{+}}$on chain length. ${ }^{[56,57]}$ 

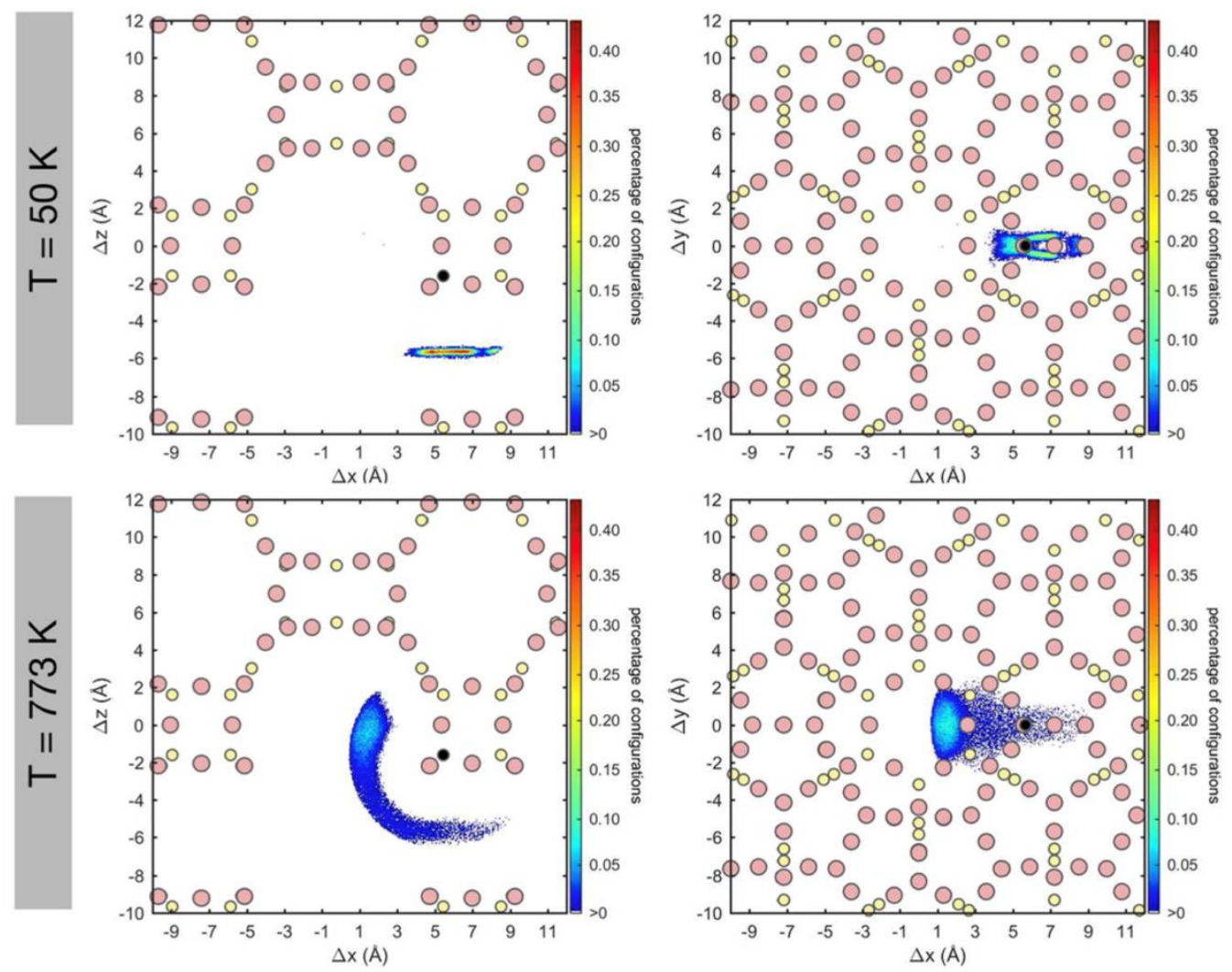

framework atoms: $\bullet \mathrm{Al} ; \circ \mathrm{Si} ; \bigcirc$

Figure 5. Heat maps showing the distribution of $\mathrm{C}$ atoms of the terminal $\mathrm{C}-\mathrm{C}$ bond of $\mathrm{n}$-butane interacting via this bond with a Brønsted acid site at site T4 in MWW, obtained from CBMC simulations at $50 \mathrm{~K}$ and at $773 \mathrm{~K}$. At $50 \mathrm{~K}$, butane is predominantly adsorbed in the sinusoidal channel, while at $773 \mathrm{~K}$, adsorption in the supercage is favored for entropic reasons. Framework atoms outside the plane represented in the heat maps have been omitted for clarity. The color scale represents the percentage of configurations in which the $\mathrm{C}$ atom is found within a square with side length $0.05 \AA$ projected onto different planes. Adapted from ref. ${ }^{[31]}$.

On the basis of their calculations of $\Delta \mathrm{H}_{\mathrm{ads}-\mathrm{H}^{+}}$and $\Delta \mathrm{S}_{\mathrm{ads}-\mathrm{H}^{+}}$from CBMC, Janda et al. suggest that the experimentally observed increase in the apparent rate coefficient for $n$-alkane cracking with increasing chain length in H-MFI is mostly due to the increase in the intrinsic rate coefficient $k_{\text {int }}$ (see eqn. 3) and, to a lesser extent, the increase in the corresponding equilibrium constant $\mathrm{K}_{\mathrm{ads}-}$ $\mathrm{H}+$ for adsorption of the alkane into the reactant state ${ }^{[24]}$ The increase in the intrinsic rate coefficient for cracking with chain length in MFI is attributed primarily to a decrease in $\Delta \mathrm{H}^{*}$ int, and $\Delta \mathrm{S}^{\ddagger}$ int is found to be relatively insensitive to chain length. In support of these conclusions, independent 
QM/MM calculations reported in the same work predict a slight decrease in $\Delta \mathrm{H}^{\ddagger}$ int with chain length and no dependence of $\Delta \mathrm{S}^{\dagger}$ int on chain length.

Different conclusions regarding the variation of $\Delta \mathrm{H}^{\ddagger}$ int and $\Delta \mathrm{S}^{\ddagger}$ int with chain length are reached when values of $\Delta \mathrm{H}_{\mathrm{ads}-\mathrm{H}^{+}}$and $\Delta \mathrm{S}_{\mathrm{ads}-\mathrm{H}^{+}}$determined from room temperature adsorption measurements are used to extract $\Delta \mathrm{H}^{\dagger}$ int and $\Delta \mathrm{S}^{\dagger}$ int. In earlier work, Bhan et al. ${ }^{[57]}$ used such adsorption data ${ }^{[58]}$ to calculate $\mathrm{K}_{\mathrm{ads}-\mathrm{H}+}$, and then $\Delta \mathrm{S}^{\ddagger}{ }_{\text {int }}$ from absolute rate theory (using independent values of $\Delta \mathrm{H}^{\ddagger}$ int obtained from ref ${ }^{[55]}$ ), from the same rate coefficients and activation energies ${ }^{[5]}$ used by Janda et al. ${ }^{[24]}$ Using this method of analysis, Bhan et al. observe, as do Janda et al., that an increase in the intrinsic rate coefficient with chain length drives an increase in the measured rate coefficient for n-alkane consumption over MFI. However, because of the different dependences of $\Delta \mathrm{H}_{\mathrm{ads}-\mathrm{H}^{+}}$and $\Delta \mathrm{S}_{\mathrm{ads}-\mathrm{H}^{+}}$on chain length for the room temperature data vs for the CBMC-calculated values, a different trend emerges from each study for how $\Delta \mathrm{H}^{\ddagger}$ int and $\Delta \mathrm{S}^{\dagger}{ }_{\text {int }}$ depend on chain length.

In a more recent experimental study, Li et al. ${ }^{[27]}$ have reported trends in $\Delta \mathrm{H}^{\ddagger}$ int and $\Delta \mathrm{S}^{\dagger}$ int with respect to alkane chain length in MFI that are qualitatively similar to those reported by Bhan et al., ${ }^{[57]} \mathrm{Li}$ et al. use infrared operando spectroscopy to infer the coverage of Brønsted acid sites at reaction conditions based on the perturbation of the zeolite $\mathrm{OH}$ stretching band at $3600 \mathrm{~cm}^{-1}$, which is caused by the specific interaction of alkanes with protons. From measurements of the coverage of protons as a function of temperature and pressure, $\mathrm{Li}$ et al. calculated thermodynamic adsorption parameters at reaction conditions. Intrinsic rate coefficients and activation parameters were then determined by using these data together with apparent rate coefficients for monomolecular cracking obtained at the same time as the adsorption measurements. 
Similar to Bhan et al., ${ }^{[57]} \mathrm{Li}$ et al. ${ }^{[27]}$ conclude that $\Delta \mathrm{H}^{\ddagger}$ int is nearly constant and that $\mathrm{k}_{\text {int }}$ increases due to an increase in $\Delta \mathrm{S}^{\dagger}$ int with chain length, although the values of $\Delta \mathrm{S}^{+}{ }_{\text {int }}$ that Li et al. obtain are less positive, and the trend with chain length significantly weaker, than those reported by Bhan et al. Li et al. thus conclude that monomolecular cracking rates of different $\mathrm{n}$-alkanes are controlled by the value of $\Delta \mathrm{S}^{\dagger}$ int, while $\Delta \mathrm{H}^{\dagger}$ int is constant both for the overall rate of cracking and for individual C-C bonds. As discussed below, the different conclusions reached by Li et al. vs. Janda et al. ${ }^{[24]}$ can be attributed to several possible factors, and demonstrate that the dependences of $\Delta \mathrm{H}^{\dagger}$ int and $\Delta \mathrm{S}^{\dagger}$ int on chain length require further investigation in order to establish whether the magnitude and direction of these dependences are general, or are a function of zeolite properties such as the Al distribution and confinement.

We first examine the explanations of Li et al. ${ }^{[27]}$ for the different trends in $\Delta \mathrm{H}^{\ddagger}$ int and $\Delta \mathrm{S}^{\ddagger}{ }_{\text {int }}$ with respect to chain length that they report vs. those reported by Janda et al. ${ }^{[24]} \mathrm{Li}$ et al. attribute the different trends primarily to the failure of the CBMC simulations of Janda et al. to account for hydrogen bonding interactions between the alkane and proton. We note that the force field we have employed does account for such interactions. Specifically, the parameters for $\mathrm{O}$ atoms bonded to Brønsted protons were modified to reflect the specific interaction of the alkane with the proton. These modified parameters were used for one of the four oxygen atoms bonded to each Al T-site. Therefore, we believe that it is unlikely that a failure to account for hydrogen bonding between the zeolite and reactant alkane contributes significantly to the different trends with chain length obtained for $\Delta \mathrm{H}^{\ddagger}$ int and $\Delta \mathrm{S}_{\text {int }}^{\ddagger}$ in our work vs that of Li et al.

Li et al. ${ }^{[27]}$ also report a systematic difference between the absolute values of $\Delta \mathrm{S}^{\ddagger}$ int that they obtain relative to the values reported by Janda et al. ${ }^{[24]}$ (see ref. ${ }^{[27]}$, Table 4), with most of the values reported by Li et al. being more positive than those reported by Janda et al. The magnitude 
and direction of this difference, however, appears to be a consequence of the fact that $\mathrm{Li}$ et al. have not treated our reported values of $\Delta \mathrm{S}^{\dagger}$ int as being corrected for the number of $\mathrm{C}$-C bonds in the alkane. This correction is implicit to the fact that we have normalized all rate coefficients by the number of C-C bonds (see ref ${ }^{[24]}$ Table 4 heading, and ref. ${ }^{[27]}$, p. 4545 ). Not accounting for this normalization causes Li et al. to overestimate the differences between our reported values of $\Delta \mathrm{S}^{\dagger}$ int and theirs. When it is correctly assumed that our reported values for $\Delta \mathrm{S}^{\ddagger}$ int are corrected for the number of C-C bonds, our values of $\Delta \mathrm{S}^{*}$ int are within experimental error of those reported by Li et al. This conclusion is based on reported $95 \%$ confidence intervals reported by Janda et al. and on twice the standard errors reported by Li et al. The absolute values of $\Delta \mathrm{H}^{+}$int for each alkane are also within experimental error between the two studies.

Although the above discussion shows that the absolute values for $\Delta \mathrm{H}^{\ddagger}$ int and $\Delta \mathrm{S}_{\text {int }}^{\ddagger}$ obtained by Li et al. ${ }^{[27]}$ do not differ significantly from those reported in our recent work, ${ }^{[24]}$ it is still notable that $\mathrm{Li}$ et al. observe a different trend in intrinsic activation parameters with respect to chain length. One possible reason for this difference is the fact that different zeolite samples were used to obtain the rate data from which $\mathrm{Li}$ et al. and Janda et al. extracted intrinsic activation parameters. It is important to consider this possibility because the Al distribution amongst different parts of the framework (e.g., channels vs. intersections) may differ between the two samples. This may lead to different trends in $\Delta \mathrm{H}^{\ddagger}$ int and $\Delta \mathrm{S}^{\dagger}$ int with respect to chain length. For example, our independent $\mathrm{QM} / \mathrm{MM}$ calculations ${ }^{[24]}$ for the T12 site in MFI (located at the channel intersections) predict that $\Delta \mathrm{H}^{\dagger}$ int decreases slightly with chain length, while $\Delta \mathrm{S}^{\star}$ int does not vary systematically with chain length. Although this finding is consistent with the trend that we have observed using previously reported experimental rate data combined with CBMC simulations, it is possible that different relationships of $\Delta \mathrm{H}^{\dagger}$ int and $\Delta \mathrm{S}^{\dagger}$ int to chain length would be obtained for Al T-sites located in other 
parts of the zeolite framework. A change in this relationship with a change in confinement would be qualitatively consistent with the observation of Eder and Lercher ${ }^{[56]}$ that the strength of the correlation of $\Delta \mathrm{S}_{\mathrm{ads}-\mathrm{H}^{+}}$and $\Delta \mathrm{H}_{\mathrm{ads}-\mathrm{H}^{+}}$for $\mathrm{n}$-alkanes adsorbed in a given zeolite depends on the confinement.

Finally, it is worth noting that the findings of Bhan et al. ${ }^{[57]}$ are sensitive to the method with which experimental adsorption data are used to extract $\Delta \mathrm{H}^{\ddagger}$ int and $\Delta \mathrm{S}^{\ddagger}{ }_{\text {int }}$ from measured rate data. As discussed in ref ${ }^{[24]}$, two sets of experimental adsorption data ${ }^{[58,59]}$ are reported in the literature for the same zeolite sample used by Narbeshuber et al. ${ }^{[55]}$ to obtain the original experimental rate measurements. Bhan et al. obtained $\Delta \mathrm{S}^{\dagger}$ int from the measured rates and activation energies of Narbeshuber et al. ${ }^{[55]}$ by using values of $\Delta \mathrm{H}_{\text {ads-H+ }}$ and $\Delta \mathrm{S}_{\text {ads-H+ }}$ reported by Eder et al. ${ }^{[58]}$ to calculate equilibrium constants for adsorption, $\mathrm{K}_{\mathrm{ads}-\mathrm{H}+}$. From values of $\mathrm{k}_{\text {app }}$ reported in $\operatorname{ref}^{[55]}{ }^{\left[\mathrm{k}_{\text {int }}\right.}$ was then determined using eqn. 3 and the calculated equilibrium constants, and $\Delta S^{\ddagger}{ }_{\text {int }}$ was extracted from $\mathrm{k}_{\text {int }}$ using absolute rate theory and independent values of $\Delta \mathrm{H}^{\mathrm{t}}$ int reported in ref ${ }^{[55]}$. This method of analysis leads to the finding of Bhan et al. that $\Delta \mathrm{H}^{\ddagger}$ int is constant while $\Delta \mathrm{S}^{\dagger}{ }_{\text {int }}$ increases strongly with chain length.

A different conclusion is reached if values of $\Delta \mathrm{H}_{\text {ads- }-\mathrm{H}+}$ and $\Delta \mathrm{S}_{\mathrm{ads}-\mathrm{H}+}$ reported by Eder et al. ${ }^{[58]}$ or by De Moor et al. ${ }^{[59]}$ are used to extract both $\Delta \mathrm{H}^{+}$int and $\Delta \mathrm{S}^{\dagger}$ int from the experimental rate data using eqns. 4 and 5 (i.e., without using independent values of $\Delta \mathrm{H}^{+}{ }_{\text {int }}$ taken from ref ${ }^{[55]}$ ). Using the adsorption data reported by De Moor et al., the same trends as those observed by Janda et al. using CBMC-calculated adsorption data are observed-i.e., that $\Delta \mathrm{H}^{*}$ int decreases with chain length while $\Delta \mathrm{S}^{\ddagger}$ int is invariant with chain length. ${ }^{[24]}$ Using the adsorption data of Eder et al. results in a weak increase of $\Delta \mathrm{S}^{*}$ int with chain length and a decrease of $\Delta \mathrm{H}^{*}$ int with chain length. ${ }^{[24]}$ On the basis of the above discussion, it can be seen that the trends in $\Delta \mathrm{H}^{\star}$ int and $\Delta \mathrm{S}^{\dagger}$ int with respect to chain length 
require further investigation, in particular to shed light on how such trends may vary with respect to active site confinement, and with the method with which $\Delta \mathrm{H}^{\ddagger}$ int and $\Delta \mathrm{S}^{\ddagger}$ int are extracted from adsorption data and experimental rate data.

\subsection{Effect of zeolite topology}

Several authors have investigated the influence of zeolite topology on the rate of monomolecular cracking of propane ${ }^{[25]}$ and n-hexane ${ }^{[10,11,26]}$. For H-FAU, H-MOR, H-BEA and H-MFI, the measured rate coefficients $\left(\mathrm{k}_{\mathrm{app}}\right)$ for the overall rate of consumption of alkane were found to increase as the measured activation energies $\left(\mathrm{E}^{*}\right.$ app $)$ decrease with decreasing pore size. Additionally, in each of these reports, the intrinsic activation energies ( $E^{+}$int $)$, calculated by subtracting experimentally determined adsorption enthalpies for non-specific adsorption anywhere in the zeolite $\left(\Delta \mathrm{H}_{\mathrm{ads}}\right)$ measured at ambient temperatures, were found to be independent of the zeolite, leading to the conclusion that higher observed cracking rates are caused by stronger adsorption rather than by differences in intrinsic activation parameters (i.e., $\Delta \mathrm{H}^{*}$ int and $\Delta \mathrm{S}_{\text {int }} .^{[10,11,25,26]}$ Ramachandran et al. later reported that a plot of $\Delta \mathrm{S}_{\text {ads }}$ vs. $\Delta \mathrm{H}_{\text {ads }}$ for $\mathrm{n}$-hexane adsorption in several zeolites shows a similar slope to that of a plot of $\ln \left(\mathrm{k}_{\text {app }}\right) \mathrm{vs} . \mathrm{E}^{\ddagger}$ app, obtained from the rate data reported in ref ${ }^{[10]}$, and concluded that the variation in measured activation parameters among zeolites is caused by differences in the adsorption thermodynamics, not the intrinsic kinetics. ${ }^{[12]}$

Using the same methodology, Kotrel et al. found that $\mathrm{E}^{*}$ int for $\mathrm{n}$-hexane monomolecular cracking is larger for H-MFI than for H-BEA and H-FAU. ${ }^{[60]}$ However, these authors attributed such differences to differences in acidity among zeolites. It is noted that differences in acidity, if present, would be expected to influence the kinetics of monomolecular activation of alkanes based 
on a number of experimental ${ }^{[5,6,61]}$ and theoretical ${ }^{[5,7,62-65]}$ studies, a subject that has recently been reviewed by Boronat and Corma ${ }^{[66]}$ and by Derouane et al. ${ }^{[49]}$ This raises the issue of whether the acidity of protons is correlated with zeolite structure and confinement, since this Minireview is focused primarily on the effects of structure and confinement on alkane cracking and dehydrogenation kinetics. Several studies have concluded that the acidity is independent of the zeolite structure and the location of the acid sites, ${ }^{[5-7]}$ but is dependent on the heteroatom ( $\mathrm{Al}, \mathrm{B}$, $\mathrm{Ti})^{[5]}$ and on the concentration of framework $\mathrm{Al}$ atoms for low values of the $\mathrm{Si} / \mathrm{Al} \mathrm{ratio}^{[67-69]}$ for which the acidity is lower as a result of the presence of Al next-nearest-neighbor pairs. Because all of the zeolites discussed in this Minireview are aluminosilicates, and nearly all of the zeolite structures studied in the works cited (with the exception of H-FAU) are highly siliceous ( $\mathrm{Si} / \mathrm{Al}$ > 8), it can be concluded that the acidity does not vary strongly among structures and therefore should not contribute significantly to observed trends in kinetics with respect to confinement. Because a detailed discussion of the factors controlling Brønsted acidity and its effects on monomolecular reaction kinetics in zeolites is outside the scope of this Minireview, the reader is referred to the references cited above for more comprehensive discussions.

Although absolute values of the intrinsic activation parameters were not reported, Gounder and Iglesia have reported relative values of measured activation energies and activation entropies $\left(\Delta S^{\dagger}{ }_{\text {app}}\right)$ for monomolecular cracking vs. dehydrogenation of a given alkane on H-FER, H-MFI, H-MOR and H-FAU, and concluded that differences in $\mathrm{E}^{*}$ app and $\Delta \mathrm{S}^{\dagger}$ app between reaction pathways are independent of the zeolite and are equal to differences in the gas phase protonation enthalpy or entropy of the relevant $\mathrm{C}-\mathrm{C}$ or $\mathrm{C}-\mathrm{H}$ bonds. ${ }^{[13,14]}$ On the basis of this interpretation, relative values of $\mathrm{E}^{\dagger}$ app and $\Delta \mathrm{S}$ app, as well as selectivities, would be expected to be structure-insensitive. However, this contradicts the previously mentioned study of propane and butane cracking over H-MOR by 
the same authors, in which differences in selectivities were attributed to "location-specific differences" in the activation entropies for reactions occurring at sites in the 8-ring side pockets vs. the 12-ring main channels of H-MOR. ${ }^{[8]}$

Janda et al. have determined both the absolute and relative values of intrinsic and apparent activation parameters for alkane cracking and dehydrogenation for eight 10-ring zeolites differing in the shape of the channels and in the size and abundance of cavities: TON, FER, -SVR, MEL, MFI, SFV, STF, and MWW (Figure 6). ${ }^{[9]}$ The authors used $\Delta \mathrm{S}_{\mathrm{ads}-\mathrm{H}+}$, calculated using CBMC, as a proxy for confinement. To extract $\Delta \mathrm{H}^{\star}$ int and $\Delta \mathrm{S}^{\star}{ }_{\text {int }}$, an improved single-step CBMC approach involving domain decomposition of $\Delta \mathrm{H}_{\text {ads }}$ and $\Delta \mathrm{S}_{\text {ads }}$ (for non-specific adsorption) was developed in order to determine values of $\Delta \mathrm{S}_{\text {ads-H+ }}$ vs. $\Delta \mathrm{H}_{\text {ads-H+ }}$ specific to protons. Using the values of $\Delta \mathrm{H}_{\text {ads- }}$ $\mathrm{H}^{+}$and $\Delta \mathrm{S}_{\mathrm{ads}-\mathrm{H}+}$ obtained in this manner at reaction temperatures, the authors were able to determine $\Delta \mathrm{H}^{\ddagger}$ int and $\Delta \mathrm{S}^{\ddagger}$ int using eqns. 4 and 5. 

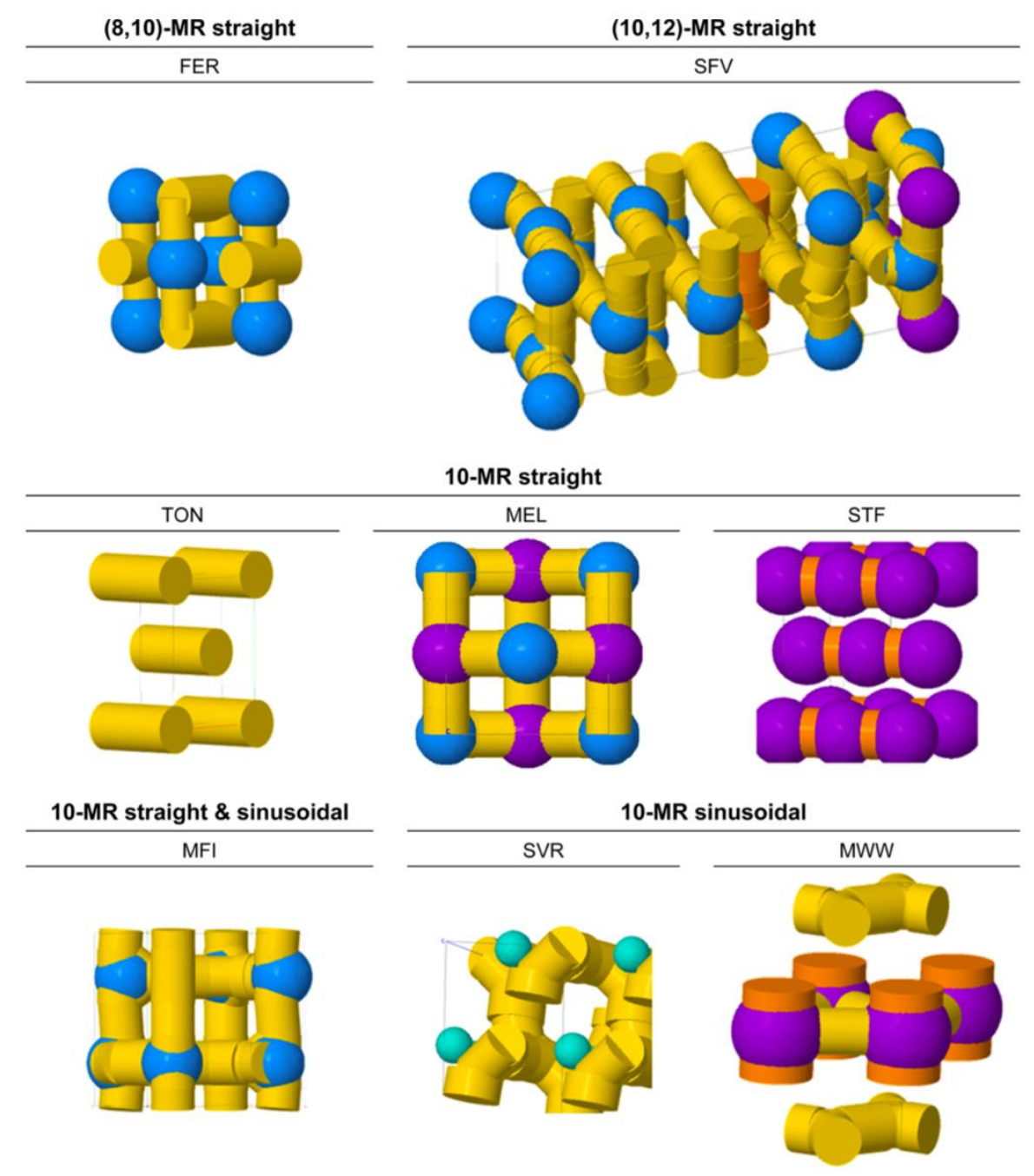

Figure 6. Series of 10-ring zeolites differing in the shape of the channels, and in the size and abundance of cavities. Representations of zeolite frameworks were generated using the ZEOMICS web tool. ${ }^{[70]}$ The channel topology (ring size and shape) is given in bold. Channels are shown in yellow ( $<6 \AA$ diameter) and orange ( $>6 \AA$ diameter). Cages are shown as green $(<6 \AA$ diameter), blue (6-8 $\AA$ diameter), and purple ( $>8 \AA$ diameter) spheres. Reproduced from ref. ${ }^{[9]}$.

Figure 7 shows apparent activation enthalpies $\left(\Delta \mathrm{H}^{*}\right.$ app $)$ and entropies $\left(\Delta \mathrm{S}^{\dagger}\right.$ app $)$, and intrinsic activation enthalpies $\left(\Delta \mathrm{H}^{\dagger}\right.$ int $)$ and entropies $\left(\Delta \mathrm{S}^{\dagger}\right.$ int $)$ as a function of the entropy of adsorption of $n$ butane adsorbed at an active site $\left(\Delta \mathrm{S}_{\mathrm{ads}-\mathrm{H}+}\right)$, Boltzmann averaged over all T-sites, which describes the average level of confinement for a zeolite in which the Al atoms are distributed randomly among the T-sites. ${ }^{[9]}$ Because the $\mathrm{Al}$ distribution is known to be nonrandom and determined by the 
$\mathrm{Si} / \mathrm{Al}$ ratio and the zeolite synthesis procedure ${ }^{[34-50]}$ where possible the apparent activation barriers were also Boltzmann averaged over multiple samples with different $\mathrm{Si} / \mathrm{Al}$ ratios. As the overall confinement increases (i.e., as $\Delta \mathrm{S}_{\text {ads-H+ }}$ decreases), $\Delta \mathrm{H}^{\ddagger}$ int and $\Delta \mathrm{S}^{\dagger}$ int for terminal cracking and dehydrogenation decrease. This observation was attributed to differences in the calculated geometries of the transition state, ${ }^{[51]}$ which for dehydrogenation involves nearly fully-formed products, and for cracking more closely resembles a protonated alkane. More confining frameworks were interpreted to confine the late transition state and restrict motion of the product fragments, causing the observed decreases in $\Delta \mathrm{H}^{\dagger}$ int and $\Delta \mathrm{S}^{\ddagger}$ int. While $\Delta \mathrm{H}^{\ddagger}$ int for central cracking does not vary significantly with $\Delta \mathrm{S}_{\text {ads-H+ }}, \Delta \mathrm{S}^{\ddagger}$ int is lower for the most confining zeolites because more entropy is lost upon protonation of the alkane to form the transition state. Selectivities for terminal cracking and dehydrogenation vs. central cracking were found to decrease because $\Delta \mathrm{S}^{\dagger}$ int decreases with increasing confinement for the former reactions. In summary, absolute values of and differences between $\Delta \mathrm{H}^{\dagger}$ int and $\Delta \mathrm{S}^{\dagger}$ int for different reaction pathways were found to be structure dependent in a manner consistent with the calculated transition-state geometries, and changes in these parameters were found to drive observed changes in selectivity with respect to confinement.

Depending on channel topology, the measured rate coefficients $\left(k_{\text {app }}\right)$ change with confinement either because of changes in $\mathrm{k}_{\text {int }}$ or because of changes in the adsorption equilibrium constant $\left(\mathrm{K}_{\mathrm{ads}-\mathrm{H}}\right)$. In both cases, the strong compensation of correlated changes in $\Delta \mathrm{H}^{+}$app and $\Delta \mathrm{S}_{\text {app }}^{\ddagger}$ and in $\Delta \mathrm{H}^{\ddagger}{ }_{\text {int }}$ and $\Delta \mathrm{S}^{\ddagger}{ }_{\text {int }}$ on the free energy barriers $\left(\Delta \mathrm{G}^{\ddagger}{ }_{\text {app }}\right.$ and $\left.\Delta \mathrm{G}^{\ddagger}{ }_{\text {int }}\right)$ at $773 \mathrm{~K}$ causes changes in the apparent and intrinsic rate coefficients with confinement to be weak relative to the strong trends observed for the activation parameters. The dependence on confinement of the latter parameters is interpreted as described above. As confinement increases, energetic and steric interactions between the zeolite and the transition state become more significant, and the product 
fragments formed can move less freely, such that $\Delta \mathrm{S}^{\dagger}$ int and $\Delta \mathrm{H}^{\dagger}$ int are related to confinement in qualitatively similar ways and are therefore positively correlated. ${ }^{[9]}$ This proposal contrasts with previous experimental studies that concluded that the intrinsic activation enthalpy ${ }^{[8,10-12,25,26]}$ and entropy ${ }^{[10,12,13]}$ are independent of structure and that observed differences in the rate for n-alkane cracking over H-MFI, H-MOR, H-BEA, and H-FAU are thus predominantly caused by differences in the adsorption thermodynamics according to eqn. 3 . The discrepancies between the conclusions of Janda et al. and the studies cited above can be attributed primarily to the different adsorption data sets used to extract $\Delta \mathrm{H}^{\ddagger}$ int and $\Delta \mathrm{S}^{\ddagger}$ int from apparent parameters using eqns. 4 and 5. Using previously reported apparent activation energies and rate coefficients for $n$-hexane monomolecular consumption over H-FAU, H-MOR and H-MFI, ${ }^{[10]}$ together with adsorption data obtained using CBMC simulations, Janda et al. found a strong dependence of $\Delta \mathrm{H}^{\ddagger}$ int and $\Delta \mathrm{S}^{\ddagger}$ int on confinement. ${ }^{[9]}$ 


\begin{tabular}{|c|c|c|}
\hline Symbols (channel type): & $\multimap$ 10-MR straight (TON, MEL, STF) $\leadsto$ 10-MR sinusoidal (SVR, MWW) & $\Delta(8,10)$-MR straight (FER) \\
\hline & $\mathrm{O} \quad(10,12)-\mathrm{MR}$ straight (SFV) $\quad \diamond 10$-MR straight \& sinusoidal (MFI) & \\
\hline
\end{tabular}
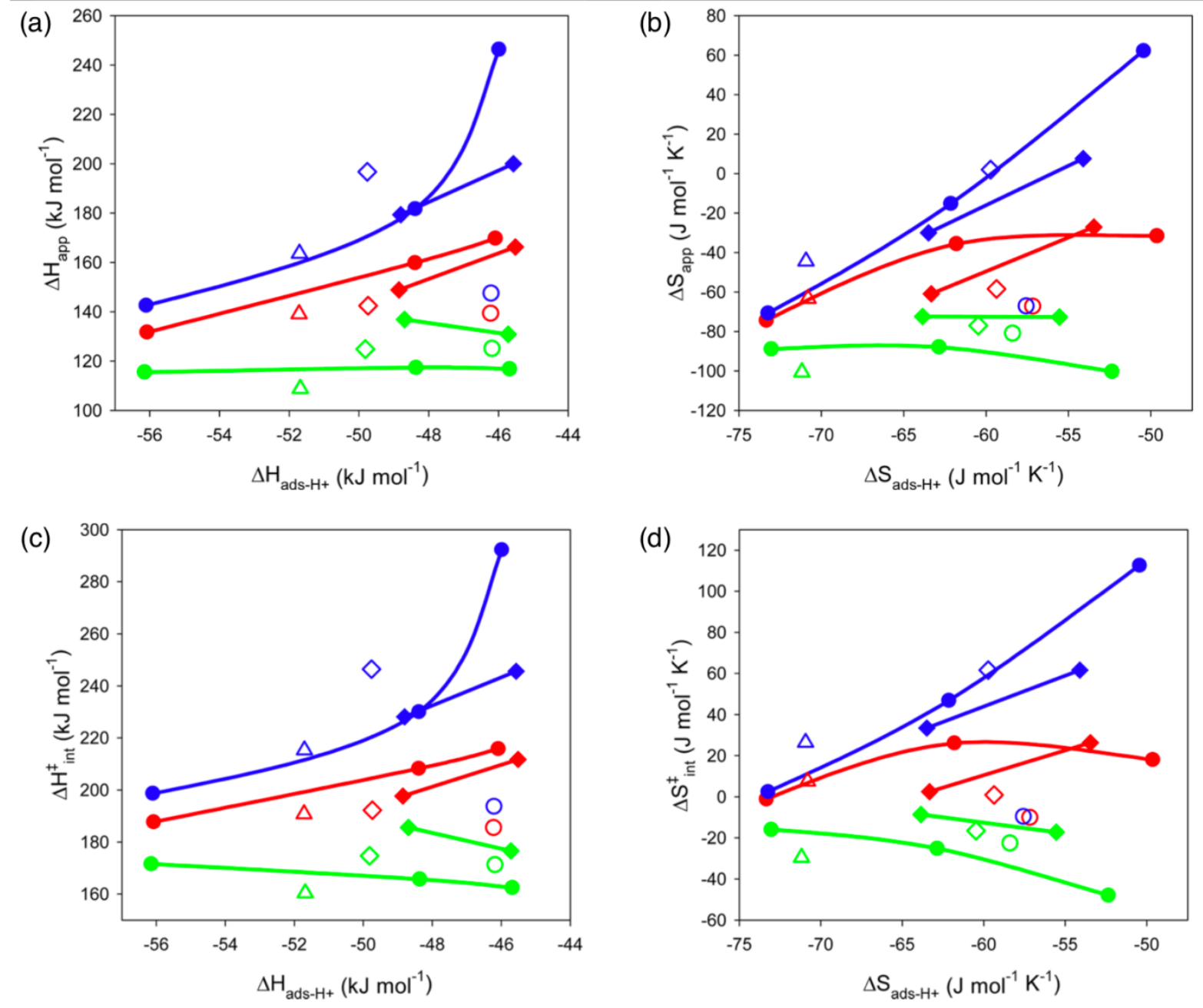

Figure 7. Plots of (a) apparent activation enthalpy vs enthalpy of adsorption, (b) apparent activation entropy vs entropy, (c) intrinsic activation enthalpy vs enthalpy of adsorption and (d) intrinsic activation entropy of adsorption for n-butane monomolecular reactions at $773 \mathrm{~K}$. Values of $\Delta \mathrm{H}_{\text {ads- } \mathrm{H}^{+}}$and $\Delta \mathrm{S}_{\text {ads-H+ }}$ were determined from CBMC simulations, and $\Delta \mathrm{H}_{\mathrm{app}}$ and $\Delta \mathrm{S}_{\text {app }}$ from measured rate data. Representative $95 \%$ confidence intervals for $\Delta \mathrm{H}_{\text {app }}^{\ddagger}$ and $\Delta \mathrm{S}_{\text {app }}^{\ddagger}$ are $\pm 7 \mathrm{~kJ}$ mol-1 and $\pm 9 \mathrm{~J} \mathrm{~mol}^{-1} \mathrm{~K}^{-1}$ for cracking, and $\pm 8 \mathrm{~kJ} \mathrm{~mol}^{-1}$ and $\pm 11 \mathrm{~J} \mathrm{~mol}_{-1} \mathrm{~K}_{-1}$ for dehydrogenation. Adapted from ref. ${ }^{[9]}$. 


\section{Quantum Chemical Studies of Reactions at Bronsted acid sites}

\subsection{QM/MM approach to describe reactions at active sites}

Theoretical studies of chemical transformations, in which bonds are broken and formed, require quantum chemical methods to describe the electronic structure of the system. Density functional theory (DFT) calculations have become the workhorse of computational chemists because of their efficient scaling with the number of atoms in the system. ${ }^{[71,72]}$ However, despite the ever-growing power of computers, the quantum chemical treatment of large systems such as zeolites still carries a high computational cost. While early studies of zeolite-catalyzed reactions relied on small cluster representations to reduce the overall number of atoms, ${ }^{[23,62,65]}$ these do not permit proper capture of the effects of the zeolite environment on the Brønsted acid sites. ${ }^{[73,74]}$ To correctly describe the crucial long-range interactions encountered by guest molecules entering the zeolite pores, a more comprehensive representation of the zeolite structure is required. This can be achieved either by periodically repeating the complete unit cell, or by using a sufficiently large cluster model.

In addition to large models, accurate density functionals, e.g., $\omega \mathrm{B} 97 \mathrm{X}-\mathrm{D},{ }^{[75,76]}$ are required to correctly describe the crucial non-bonding interactions encountered by guest molecules entering the zeolite pores. The hybrid quantum mechanics/molecular mechanics approach (QM/MM) in which a small region around the active site and the adsorbates are treated with quantum mechanics while the remainder of the system is described with a classical force field has enabled routine calculations on zeolite systems. ${ }^{[77]}$ In these simulations, the QM region is typically a small $5 \mathrm{~T}$ cluster comprising the $\mathrm{Al}$ atom and its neighboring $\mathrm{Si}$ atoms and any guest molecules interacting with the Brønsted acid site. Figure 8 shows such a QM/MM model for H-MFI with an acid sited located at the T12 position. The main advantage of the QM/MM approach lies in its favorable 
balance between the computational cost and the accuracy for parameters that depend on both a precise description of the chemistry occurring at the active site and the inclusion of the long-range effects of the zeolite environment, e.g. intrinsic reaction energies. A complete discussion of the merits and limitations of all the different model systems and electronic structure methods that have been employed in studies of adsorption and catalysis in zeolites is beyond the scope of this Minireview. Pidko has recently given a detailed argumentation of how the success of computational approaches to complex catalytic systems such as zeolites hinges on finding the right compromise between zeolite representation and method accuracy. ${ }^{[78]}$ We also refer the reader to recent reviews for a more detailed discussion of these topics. ${ }^{[74,79,80]}$

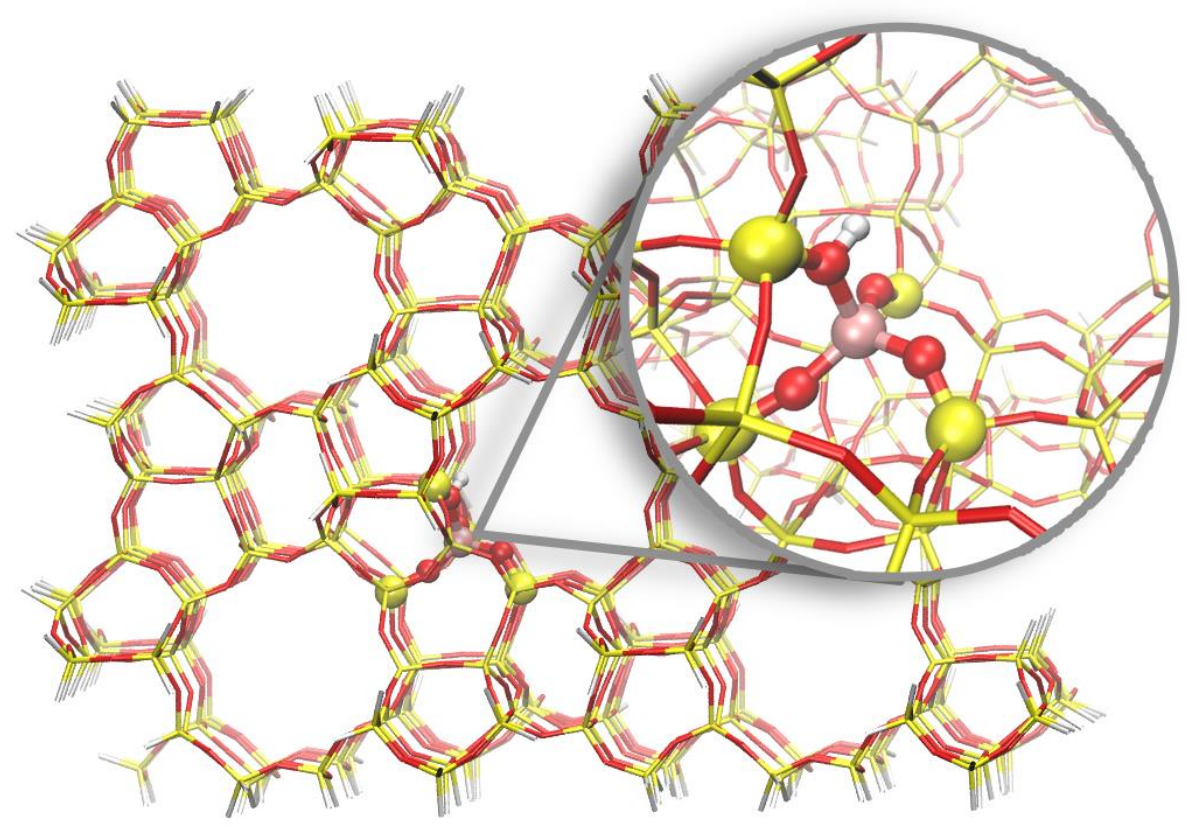

Figure 8. QM/MM model for H-MFI based on a large 437 T-atom cluster. A small sub-cluster of 5 T-atoms surrounding the Brønsted acid site is treated quantum mechanically, while the remainder of the model is described with a classical force field. The QM region is depicted using a ball-andstick representation. $\mathrm{Si}$ atoms are shown in yellow, $\mathrm{O}$ in red, $\mathrm{Al}$ in pink, and $\mathrm{H}$ in white. 
Gomes et al. have shown that the accuracy of QM/MM energies is relatively insensitive to the size of the QM region, and that convergence of the thermochemical properties can be achieved by using large clusters (> 150 T-atoms) combined with large basis sets (e.g., 6$311++\mathrm{G}(3 \mathrm{df}, 3 \mathrm{pd})) .{ }^{[77]}$ A set of MM parameters (P1) for the zeolite atoms was developed by Zimmerman et al. to approximate adsorption energies and transition states obtained from full QM calculations at the $\omega \mathrm{B} 97 \mathrm{X}-\mathrm{D} / 6-31+\mathrm{G}^{* *}$ level of theory. ${ }^{[81]}$ However, these parameters were subsequently found to overestimate binding energies of alkanes compared with experimental values, particularly for larger adsorbate molecules such as pentane and hexane. ${ }^{[51]} \mathrm{Li}$ et al. have shown that this increasing deviation is caused by overestimation of the van der Waals interactions between the adsorbates and the zeolite by the pairwise-additive Lennard-Jones potential in P1, and derived an updated set of parameters $(\mathrm{P} 2)$ by recalibrating its characteristic energies. ${ }^{[82]}$ Using the P2 parameter set, experimentally measured physisorption and chemisorption energies can be reproduced with errors about five times smaller than obtained using the P1 parameter set (Figure 9). ${ }^{[82]}$

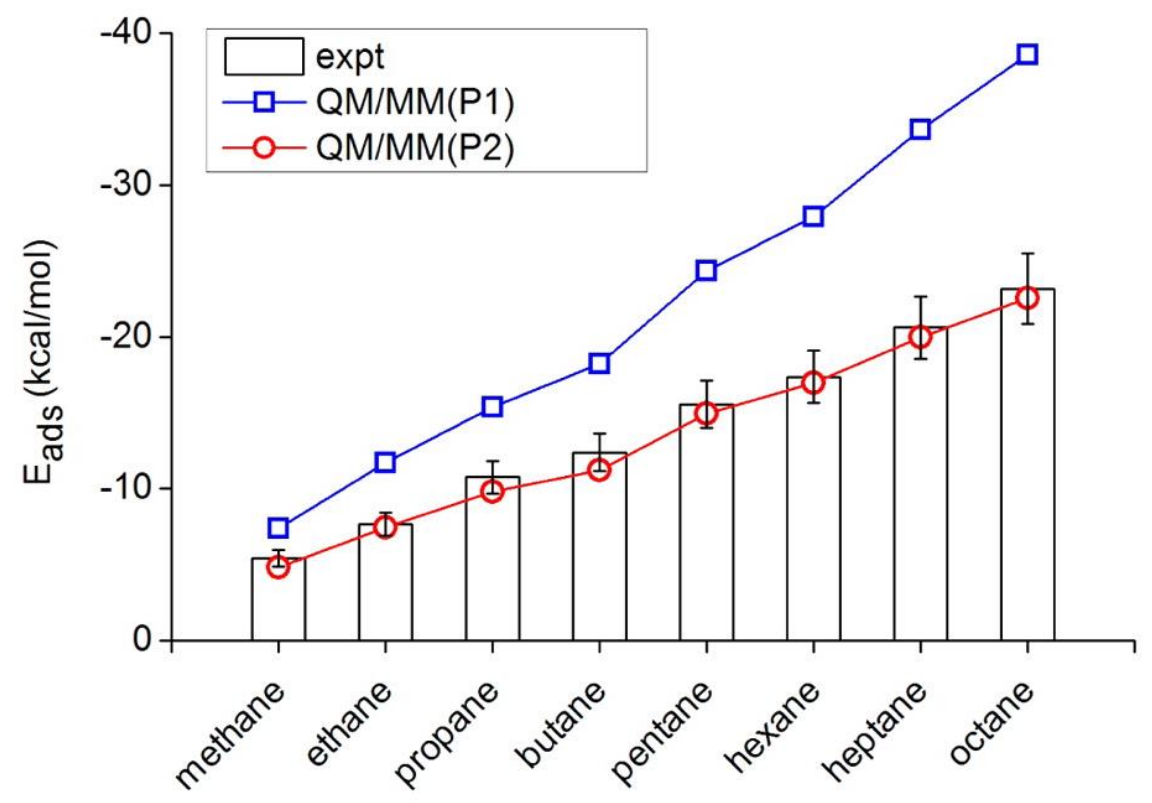


Figure 9. Adsorption energies of guest molecules in purely siliceous MFI calculated with QM/MM(P1) and $\mathrm{QM} / \mathrm{MM}(\mathrm{P} 2)$. Experimental values are shown with $\pm 10 \%$ error bar and were derived by removing zeropoint vibrational and temperature corrections from experimentally measured adsorption enthalpies using quasi-RRHO. ${ }^{[83]}$ The connecting lines are drawn to guide the eye. Adapted from ref. ${ }^{[82]}$.

\subsection{Insights for n-butane cracking and dehydrogenation kinetics from $Q M / M M$}

Sharada et al. have applied the QM/MM scheme to a cluster model containing 437 T-atoms to investigate central and terminal cracking and dehydrogenation of n-butane in H-MFI. ${ }^{[51]}$ The reactions were modeled at two $\mathrm{Al}$ sites to investigate the effects of acid site location: $\mathrm{Al}$ in $\mathrm{T} 12$, which places a Brønsted acid at the intersection of the straight and sinusoidal channels, and $\mathrm{Al}$ in T10, which places a Brønsted site within the sinusoidal channel. Central and terminal cracking were shown to occur through an early transition state in which the proton attacks the $\mathrm{C}-\mathrm{C}$ bond in the alkane (Figure 10.a and 10.b). Dehydrogenation was found to proceed through a late transition state in which the $\mathrm{H}_{2}$ molecule is almost fully formed (Figure 10.c and 10.d). ${ }^{[51]}$ 

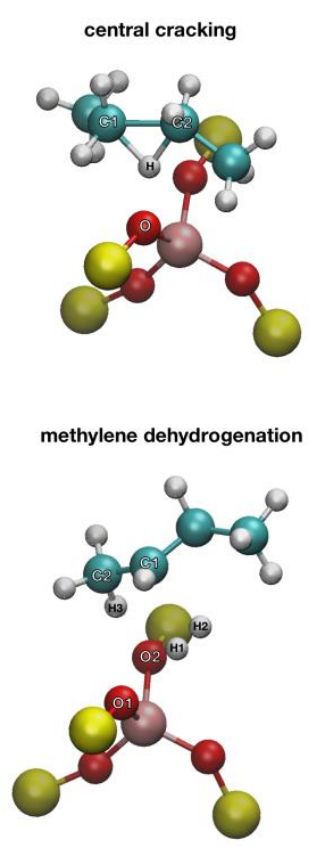

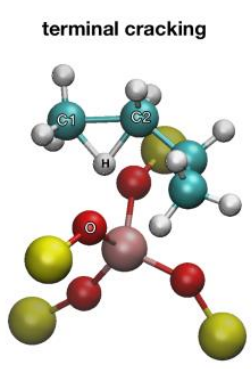

methyl dehydrogenation

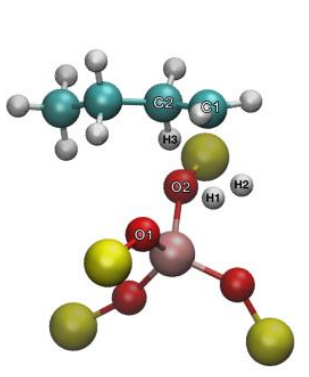

Figure 10. Transition state geometries for central cracking, terminal cracking, methylene dehydrogenation, and methyl dehydrogenation in MFI, with Al placed in the T12 site. For clarity, only the atoms included in the $\mathrm{QM}$ region are shown. Si atoms are shown in yellow, $\mathrm{O}$ in red, $\mathrm{Al}$ in pink, $\mathrm{C}$ in cyan, and $\mathrm{H}$ in white. ${ }^{[51]}$ Figure reproduced from ref. ${ }^{[31]}$.

Intrinsic activation energies calculated for reactions at the $\mathrm{T} 10$ site are larger than those at T12 owing to differences in interaction of the substrate with the acid site as well as with the zeolite framework, demonstrating that Brønsted acid sites in H-MFI are not equivalent for these reactions. ${ }^{[51]}$ This conclusion supports the experimental observations of Janda and Bell that changes in the activity and selectivity of butane cracking and dehydrogenation arise from changes in the distribution of $\mathrm{Al}$ atoms and the associated Brønsted acid sites as a consequence of changes in the $\mathrm{Si} / \mathrm{Al}$ ratio of the zeolite. ${ }^{[22]}$

Van der Mynsbrugge et al. have conducted a theoretical study of cracking and dehydrogenation in a series of zeolites containing 10-ring channels and differing in cavity size (TON, FER, -SVR, MFI, MEL, STF, and MWW). ${ }^{[31]}$ This effort was undertaken to corroborate the conclusion of Janda et al., who observed that variations in reaction rates depend not only on 
differences in $\Delta \mathrm{H}_{\text {ads-H+ }}$ and $\Delta \mathrm{S}_{\text {ads-H+ }}$, but also on differences in $\Delta \mathrm{H}^{*}$ int and $\Delta \mathrm{S}^{\ddagger}{ }_{\text {int }}{ }^{[9]}$ While QM/MM calculations have provided good estimates of the intrinsic enthalpies and entropies of activation extracted from experimental rate data for MFI, extending this approach to less confining zeolites is not straightforward, particularly for activation entropies. ${ }^{[31]}$ Because quantum chemical calculations are very resource intensive, they are necessarily limited to one (or a few) configurations of selected acid sites. However, as discussed above, experimentally measured heats of adsorption and kinetic parameters represent ensemble averages over all possible configurations of the alkane around Brønsted acid protons associated with a variety of $\mathrm{Al}$ sites. ${ }^{[24]}$ In principle, calculations should be performed for all the different Al sites within the zeolite and the Boltzmannaveraged values should be used to compare with experimental adsorption data and rate parameters. In practice, though, resource limitations require the selection of a representative T-site to carry out QM/MM calculations. In our recent study, ${ }^{[31]}$ we have used CBMC-derived site-specific entropies of adsorption $\left(\Delta \mathrm{S}_{\mathrm{ads}-\mathrm{H}+}\right)$, shown by Janda et al. ${ }^{[9]}$ to provide a practical metric for confinement, in order to inform the selection of representative T-sites in the series of 10-ring zeolites. In addition, we ensured that the range of structural environments sampled was representative of the changes in confinement encountered by reactant and transition states (TS) in moving from zeolites with higher average confinement (i.e., lower values of $\Delta \mathrm{S}_{\mathrm{ads}-\mathrm{H}+}$ ) to zeolites with lower average confinement (i.e., higher values of $\Delta \mathrm{S}_{\mathrm{ads}-\mathrm{H}+}$ ), and took into account the above-mentioned tendency of the adsorbed alkane to redistribute preferentially within less confining spaces (e.g., cages, if present, rather than channels) at higher temperatures. Selection of T-sites in this way ensures that changes in confinement occur for reactant and transition states (TS) in moving from zeolites with higher average confinement (i.e., more negative values of $\Delta \mathrm{S}_{\mathrm{ads}-\mathrm{H}^{+}}$) to zeolites with higher average confinement (i.e., less negative values of $\Delta \mathrm{S}_{\text {ads-H+ }}$ ). ${ }^{[31]}$ 


\subsection{Thermochemical calculations}

Thermochemistry and reaction kinetics in DFT studies follow from a normal mode analysis on the stationary points that correspond to the reactant and transition states. While activation enthalpies are largely determined by the electronic energy barrier between the reactant and transition states predicted by the electronic structure method, entropies are derived from the partition functions, therefore their accuracy depends on the appropriate treatment of the normal modes. Treating the low-frequency motions that correspond to translational and rotational movements of the guest molecule relative to the zeolite host as vibrations under the rigid rotorharmonic oscillator (RRHO) approximation has been shown to overestimate the entropy losses associated with the adsorption of the guest molecules from the gas phase into the zeolite pores. ${ }^{[59,84,85]}$

In their study of hydrocarbon adsorption in zeolites, De Moor et al. demonstrated that the entropy cannot be calculated correctly by treating the guest molecules as immobile adsorbates in the RRHO approximation, and that the remaining mobility of the adsorbed species at the active sites needs to be taken into account. ${ }^{[85]}$ The authors suggested an alternative, mobile adsorbate calculation, which uses a so-called mobile block analysis of the Hessian $(\mathrm{MBH})^{[86,87]}$ to identify those low-frequency modes corresponding to overall global translations and rotations of the guest molecule relative to the framework. Once identified, the contributions of the modes to the partition function are replaced by the correct ones for translational or rotational motions.

While the $\mathrm{MBH}$ analysis provides an unambiguous identification of the modes to be treated as translations or rotations, the calculation of the corresponding translational entropy still depends upon an ad hoc estimate of the extent of the translational motion. Several authors have proposed 
alternative ways to address the anharmonicity of low-frequency modes and improve the accuracy of thermochemical calculations. Piccini and Sauer proposed the use of fourth and sixth order polynomials to represent the potential energy surface of the individual normal modes in loosely bound adsorption complexes. ${ }^{[88,89]}$ Using this method, they achieved agreement between calculated and experimental adsorption free energies for methane, ethane and propane in H-CHA within 3 $\mathrm{kJ} / \mathrm{mol} .{ }^{[89]}$ While the use of low-order polynomial functions is computationally advantageous, the quality of agreement between the model and the real potential energy surface for a given system can be difficult to assess. In an effort to develop a more general approach, Li et al. suggested representing the potential energy surface of each normal mode by interpolating the energies of a series of geometries distorted along that mode.${ }^{[90]}$ Additionally, these authors introduced a scheme, dubbed UM-VT, in which internal rotations are projected out of the Hessian and treated separately from the remaining vibrations, resulting in significantly improved agreement with experimental standard entropies and heat capacities for a series of gas phase molecules. The UM-VT scheme might afford similar improvements for zeolite systems, however, some practical limitations arise when not all atoms are chemically bonded. For loosely-bound complexes, the appropriate cutoff point for the sampling along specific modes is not inherently clear. If the cutoff is set too low, the mobility of the adsorbate (and thus the entropy) will be underestimated. If the cutoff is set too high, the calculation will include configurations in which the adsorbate starts to diffuse away from the active site, no longer occupying the adsorbed state. More research is required on this particular issue. Note that these concerns also apply to the approach followed by Piccini and Sauer, ${ }^{[89]}$ but is not specifically addressed in their reports.

Grimme has proposed another, more pragmatic, strategy to address anharmonicity of lowfrequency modes, using a systematic interpolation between a one-dimensional free rotor at low 
frequencies and a harmonic oscillator at high frequencies. ${ }^{[83]}$ Although enthalpies are decidedly less sensitive to the inaccurate treatment of the normal modes, Li et al. have shown that applying the quasi-RRHO approach to evaluate zero-point energies and thermal corrections can also improve the values for the adsorption enthalpies of molecules in zeolites. ${ }^{[82]}$ In this case, the energy contributions for all modes are replaced by an interpolation between the contribution of a harmonic oscillator and that of a translational or rotational mode. Adsorption energies calculated with $\mathrm{QM} / \mathrm{MM}$ using the $\mathrm{P} 2$ parameter set (see above) and the quasi-RRHO approximation agree with experimental values with an RMS error of $1.8 \mathrm{kcal} / \mathrm{mol}$ for both nonpolar and polar molecules adsorbed in MFI, H-MFI, and H-BEA. ${ }^{[82]}$

Janda et al. have shown that the quasi-RRHO approach can estimate intrinsic activation enthalpies and entropies for central and terminal cracking of propane through n-hexane in H-MFI in good agreement with experiments. ${ }^{[24]}$ However, since this approach still relies upon a single geometry for both the reactant and transition state, which at finite temperature consists of an ensemble of similar structures with slightly different orientations, it is expected to break down for zeolites that are less confining than H-MFI. Since the entropy (and enthalpy) of the transition states will still be underestimated, apparent activation enthalpies and entropies will be underestimated. If the reactant and transition states undergo differing degrees of global translation and rotation, intrinsic activation enthalpies and entropies will also be under- or overestimated. This hypothesis was confirmed in the recent theoretical work by Van der Mynsbrugge et al. of butane cracking and dehydrogenation in 10-ring zeolites with different degrees of confinement. ${ }^{[1]}$ Thermal corrections to the apparent enthalpies and entropies derived from CBMC simulations on the reactant state (butane adsorbed at the Brønsted acid site), which naturally account for anharmonic motions of the adsorbate in the vicinity of the active site, were shown to enable inclusion of configurational 
effects at low computational cost. ${ }^{[31]}$ If the number of configurations in the transition state ensemble is roughly similar to the number of configurations in the reactant state, the configurational contributions to the enthalpy $\left(\Delta \Delta \mathrm{H}_{\text {config }}\right)$ and entropy $\left(\Delta \Delta \mathrm{S}_{\text {config }}\right)$ of the transition state can be estimated from the difference between the values of $\Delta \mathrm{S}_{\text {ads-H+ }}$ at $773 \mathrm{~K}$ calculated from QM/MM using the quasi-RRHO approach and those determined from CBMC simulations on butane adsorption at $\mathrm{Al}$ in the same $\mathrm{T}$-site:

$$
\Delta \Delta \mathrm{H}_{\text {config }}=\Delta \mathrm{H}_{\text {ads- } \mathrm{H}+}(\mathrm{CBMC} ; 773 \mathrm{~K})-\Delta \mathrm{H}_{\text {ads }-\mathrm{H}+}(\mathrm{QM} / \mathrm{MM}-\mathrm{qRRHO} ; 773 \mathrm{~K})
$$

and

$$
\Delta \Delta \mathrm{S}_{\text {config }}=\Delta \mathrm{S}_{\text {ads-H }}(\mathrm{CBMC} ; 773 \mathrm{~K})-\Delta \mathrm{S}_{\text {ads- } \mathrm{H}+}(\mathrm{QM} / \mathrm{MM}-\mathrm{qRRHO} ; 773 \mathrm{~K})
$$

The values of $\Delta \Delta \mathrm{H}_{\text {config }}\left(10-43 \mathrm{~kJ} \mathrm{~mol}^{-1}\right)$ and $\Delta \Delta \mathrm{S}_{\text {config }}\left(62-86 \mathrm{~J} \mathrm{~mol}^{-1} \mathrm{~K}^{-1}\right)$ depend strongly on the shape and size of the zeolite pores, and on the location of the active sites within the pores. ${ }^{[31]}$ For central cracking, values of $\Delta \mathrm{H}^{*}$ app and $\Delta \mathrm{S}^{\ddagger}$ app calculated using the quasi-RRHO approach are underestimated, especially for the less confining zeolites (Figure 11.a and 11.b). Adding the CBMC corrections significantly improves the agreement for $\Delta \mathrm{H}^{\ddagger}$ app and $\Delta \mathrm{S}^{\dagger}$ app in all zeolites, which indicates that the configurational enthalpy and entropy of the transition state are fairly similar to those of the reactant state, consistent with the early character of the central cracking transition state ${ }^{[51]}$ By contrast, for dehydrogenation, adding the CBMC corrections only improves the agreement between $\Delta \mathrm{H}^{\ddagger}$ app and $\Delta \mathrm{S}^{\ddagger}$ app from theory and experiment for the zeolites with the most confining structures (Figure 11.c and 11.d). As the confinement decreases, theory increasingly underestimates the experimental values of $\Delta \mathrm{H}^{\ddagger}$ app and, more strongly, $\Delta \mathrm{S}^{\dagger}$ app. This deviation is attributed to the fact that dehydrogenation occurs via a late transition state, and the CBMC 
corrections derived from the reactant state fail to account for the uncorrelated rotations and translations of the product-like fragments making up the transition state. ${ }^{[31]}$

(a)

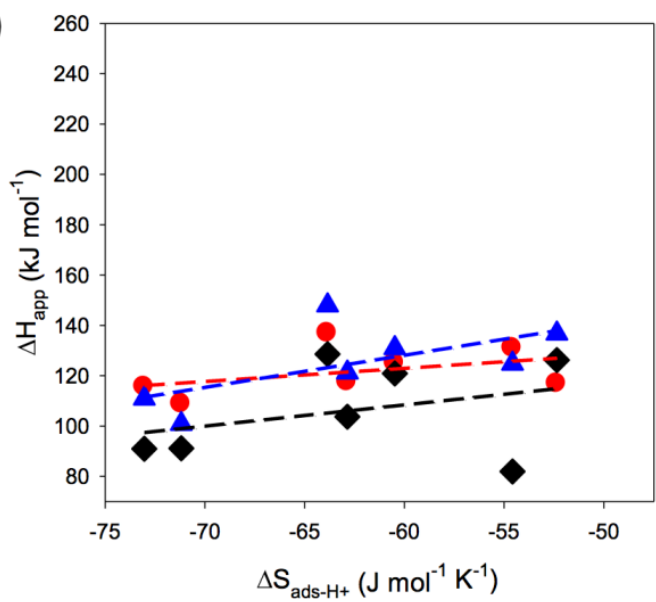

(c)

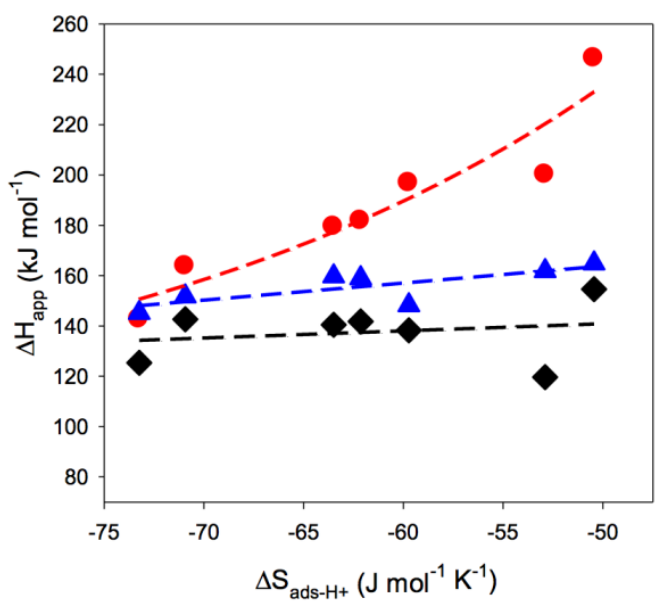

(b)

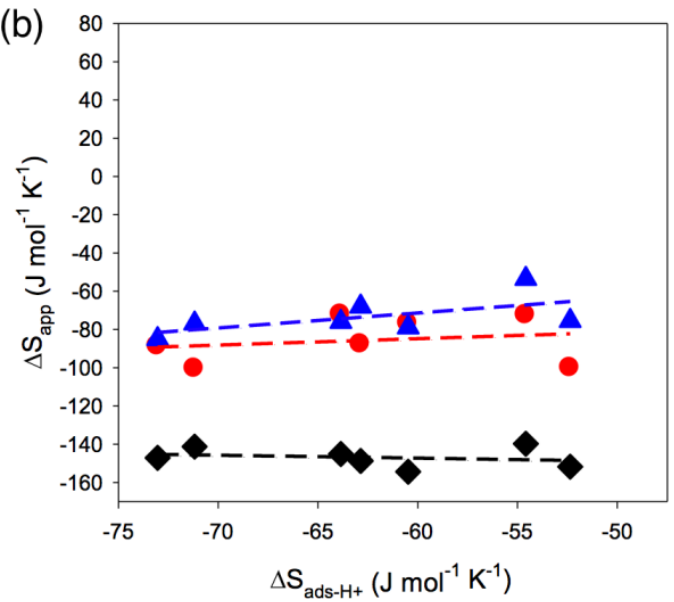

(d)

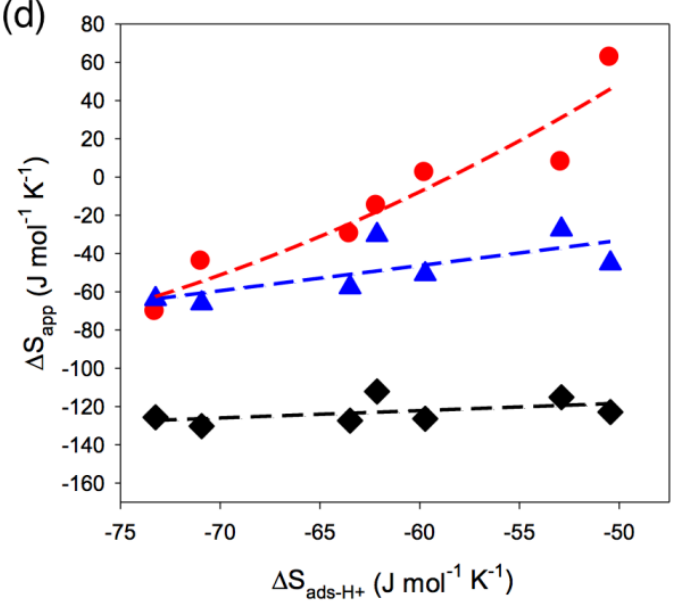

Figure 11. Plots of apparent activation enthalpy $(a, c)$ and entropy $(b, d)$ vs adsorption entropy determined from CBMC simulations for central cracking $(a, b)$ and central dehydrogenation $(c, d)$ of n-butane at $773 \mathrm{~K}$. Experimental values (red circles) are compared with theoretical values determined from QM/MM using the quasi-RRHO approach, before (black diamonds) and after (blue triangles) adding the thermal corrections derived from CBMC simulations. Representative $95 \%$ confidence intervals for the experimental values of $\Delta \mathrm{H}^{\ddagger}$ app and $\Delta \mathrm{S}^{\ddagger}$ app are $\pm 8 \mathrm{~kJ} \mathrm{~mol}^{-1}$ and $\pm 11 \mathrm{~J} \mathrm{~mol}^{-1} \mathrm{~K}^{-1}$. Adapted from ref. ${ }^{[31]}$. 


\section{Conclusion and Outlook}

Our review shows how confinement of Brønsted acid sites in zeolites can influence the observed kinetics of monomolecular cracking and dehydrogenation of alkanes. The environment of the active sites varies with the distribution of the $\mathrm{Al}$ atoms in the framework of a given zeolite as a function of the $\mathrm{Si} / \mathrm{Al}$ ratio and with the overall topology of the zeolite. To understand the origin of these observations, it is important to separate the contributions of the adsorption thermodynamics and the intrinsic kinetics to the apparent kinetics. The configurational-bias Monte Carlo (CBMC) approach described by Janda et al. ${ }^{[9,24,32]}$ has provided a computationally efficient tool to describe adsorption of gas phase alkanes into the reactant state (i.e., in configurations in which the alkanes are close enough to a Brønsted acid site for cracking or dehydrogenation to occur) at reaction temperatures $(>673 \mathrm{~K})$, such that the corresponding enthalpy $\left(\Delta \mathrm{H}_{\mathrm{ads}-\mathrm{H}^{+}}\right)$and entropy $\left(\Delta \mathrm{S}_{\mathrm{ads}-\mathrm{H}+}\right)$ changes can be determined correctly and accurate intrinsic activation parameters can be extracted from experimental apparent activation parameters.

Using this approach, the intrinsic enthalpies of activation for dehydrogenation have been found to increase with a decrease in the confinement of the proton, using the entropy of adsorption as a proxy for confinement. ${ }^{[9,24]}$ By contrast, the intrinsic activation parameters for central cracking are generally insensitive to confinement and those for terminal cracking exhibit intermediate dependence on confinement. Progress in understanding the origin of these differences in sensitivity to confinement as a function of reaction pathway has been made using quantum chemical calculations as summarized below. In addition, the intrinsic activation parameters for $\mathrm{n}$-alkane

cracking have been determined as a function of chain length for MFI. ${ }^{[9,24]} \mathrm{A}$ decrease of the intrinsic activation energy was found to drive an increase of the rate coefficient with chain length while the intrinsic activation entropy was invariant with chain length, a finding that is consistent 
with independent QM/MM calculations. However, more recent experimental work ${ }^{[27]}$ in which different conclusions have been reached demonstrates that the variation of activation parameters with chain length is not fully resolved. Further investigation is necessary in order to determine whether the dependence of these parameters on chain length is general or is a function of confinement. Of note is that understanding the structure and chain length dependence of intrinsic activation parameters has been enabled by the abovementioned Monte Carlo technique, which allows intrinsic barriers to be extracted from measured barriers correctly by providing enthalpy and entropy of adsorption to the reactant state at the temperature of the reaction. This method of analysis leads to different conclusions regarding the structure dependence (or lack thereof) of intrinsic activation parameters than those previously reported, which were calculated from measured activation barriers and experimental adsorption data obtained at room temperature. ${ }^{[8,10-}$ $13,25,26]$

Hybrid quantum mechanics/molecular mechanics (QM/MM) calculations on large cluster models have enabled the computational study of reactions occurring at active sites with the necessary accuracy at a reasonable computational cost. Once stationary points corresponding to the reactant and transition states have been identified, thermodynamic and kinetic parameters can be calculated from a normal mode analysis, which provides the contributions of the nuclear motions to the partition function. However, the correct treatment of the often strongly anharmonic, low-frequency motions of species in the both reactant and transition states remains a challenge. These motions typically correspond to translational and rotational movements of guest molecules relative to the zeolite host, and describing them as vibrations under the rigid rotor-harmonic oscillator (RRHO) approximation results in overestimated entropy losses of these guest molecules inside the zeolite pores compared to the gas phase. The ultimate shortcoming of this approach is 
that it relies on a single geometry for both the reactant and transition state, which at finite temperature consist of an ensemble of structures with different orientations. If the reactant and transition states undergo similar motions around the active site, configurational corrections determined from CBMC simulations on the reactant state can be a pragmatic solution. In the context of monomolecular alkane cracking and dehydrogenation, this approach was found to work well for central cracking, which proceeds through an early transition state that closely resembles the reactant, but not for dehydrogenation, which involves a late transition state in which the product fragments are almost fully formed. ${ }^{[51]}$ The motions of these fragments relative to each other and to the zeolite differ significantly from those in the reactant state, especially in less confining zeolites. The treatment of such reactions, involving such loose transition states in large-pore zeolites is a challenge for future research efforts. In a similar approach to the one followed by Van der Mynsbrugge et al., ${ }^{[31]}$ one might consider attempting to derive configurational corrections for reactions with a late transition state based on the product state instead of the reactant state. While this may certainly be possible in some cases, this is not an option in the case of alkane dehydrogenation, since the interaction of the alkene formed in this reaction with the acid site cannot be described with the classical force fields used in CBMC simulations, and a first principle approach is required. Alkenes rapidly undergo protonation, even at low temperatures, and the nature of the intermediates formed under reaction temperatures remains unclear. Recent studies using ab initio molecular dynamics have shown that alkenes interacting with Brønsted acid sites can form a $\pi$-complex, a carbenium ion or a covalently bound alkoxide, depending on the temperature, the chain length of the alkene and the degree of branching. ${ }^{[91,92]}$

The products formed immediately after crossing the transition state for alkane cracking or dehydrogenation are metastable intermediates that are separated from more stable species by 
relatively small barriers that are easily overcome at reaction temperatures. Zimmerman et al. have employed quasi-classical trajectory simulations with initial nuclear velocities derived from the QM populations of the vibrational modes in the transition state at reaction temperatures to investigate the non-equilibrium pathways through which the carbenium ion intermediates formed by the protonation of C-C bonds in n-pentane evolve into a variety of cracking products. The prevailing pathways, which ultimately determine the experimentally observed product selectivity for $n-$ pentane cracking in H-MFI, were shown to deviate significantly from the potential energy surface at $0 \mathrm{~K}$ obtained from static electronic structure calculations. ${ }^{[93]}$ More recently, Gomes et al. demonstrated similar differences between product distributions predicted from static and dynamic pathways for the zeolite-catalyzed methylation of ethene and propene by methanol. ${ }^{[94]}$

With the increasing availability of more powerful computers, several research groups have started to explore the use of ab initio molecular dynamics (AIMD) methods ${ }^{[95]}$ on zeolite systems. These emerging applications of AIMD methods to problems in zeolite catalysis have been reviewed recently by Van Speybroeck et al. ${ }^{[74,96]}$ While molecular dynamics methods provide natural access to the free energy surfaces at reaction temperatures, the time scale that can be studied in an AIMD simulation is in the order of $\sim 100 \mathrm{ps}$ at best. Even for chemical reactions with a high turnover frequency, the probability of the reaction occurring in a given $100 \mathrm{ps}$ window is extremely low. To enable the study of such rare events with molecular dynamics, specific techniques are required to enhance their sampling by forcing the system to cross the free energy barrier associated with the reaction of interest. ${ }^{[97-102]}$

Laio and Parrinello introduced the metadynamics method to reconstruct the free energy surface as a function of one or more so-called collective variables. ${ }^{[97,103-105]}$ This approach has been applied to zeolite-catalyzed reactions. ${ }^{[1,92,106-108]}$ The success of this approach depends on whether 
the reaction coordinate for the reaction of interest can be uniquely described as a function of such collective variables. This can be particularly challenging in the case of zeolite-catalyzed conversion of hydrocarbons, since hydrocarbons contain many equivalent $\mathrm{C}$ and $\mathrm{H}$ atoms, which can easily be scrambled via rapid isomerization reactions. As an alternative to the metadynamics approach, the free energy barrier associated with a chemical reaction can also be determined by performing thermodynamic integration over a series of constrained molecular dynamics simulations along the reaction coordinate. ${ }^{[98,109]}$ If the reaction coordinate is not known a priori (or if the objective is to discover new reaction mechanisms), the transition path sampling method is a powerful, yet very computationally intensive option. ${ }^{[110,111]}$ Transition path sampling combines Monte Carlo techniques with molecular dynamics approaches to generate an ensemble of trajectories between specified reactant and product states through perturbations or 'shooting moves' on an initial path connecting those reactants and products. ${ }^{[110,111]}$ Reaction rate coefficients and selectivities can then be calculated from this ensemble of transition paths, as demonstrated by Bučko et al. for propane dehydrogenation on chabazite. ${ }^{[112]}$

\section{Acknowledgements}

This work was supported by a grant from Chevron Energy Technology Company. J.V.d.M. and V.V.S. also acknowledge funding from the Ghent University Special Research Fund (BOF).

\section{References}

[1] A. Corma, Chem. Rev. 1995, 95, 559-614.

[2] M. Guisnet, J. P. Gilson, Zeolites for Cleaner Technologies, Imperial College Press, London, 2002. 
W. Vermeiren, J. P. Gilson, Top Catal 2009, 52, 1131-1161.

[4] N. Rahimi, R. Karimzadeh, Appl. Catal. A Gen. 2011, 398, 1-17.

[5] A. J. Jones, R. T. Carr, S. I. Zones, E. Iglesia, J. Catal. 2014, 312, 58-68.

[6] E. G. Derouane, D. Chang Clarence, Micro. Meso. Mater. 2000, 35-36, 425-433.

[7] A. J. Jones, E. Iglesia, ACS Catal. 2015, 5, 5741-5755.

[8] R. Gounder, E. Iglesia, J. Am. Chem. Soc. 2009, 131, 1958-1971.

[9] A. Janda, B. Vlaisavljevich, L.-C. Lin, B. Smit, A. T. Bell, J. Am. Chem. Soc. 2016, $138,4739-4756$.

[10] J. A. van Bokhoven, B. A. Williams, W. Ji, D. C. Koningsberger, H. H. Kung, J. T. Miller, J. Catal. 2004, 224, 50-59.

[11] J. A. van Bokhoven, B. Xu, Stud. Surf. Sci. Catal. 2007, DOI 10.1016/S01672991(07)80974-8.

[12] C. E. Ramachandran, B. A. Williams, J. A. van Bokhoven, J. Catal. 2005, 233, 100108.

[13] R. Gounder, E. Iglesia, Acc. Chem. Res. 2012, 45, 229-238.

[14] R. Gounder, E. Iglesia, Chem. Commun. 2013, 49, 3491-3509.

[15] J. Weitkamp, S. Ernst, L. Puppe, in Catalysis and Zeolites, Springer, Berlin, Heidelberg, Berlin, Heidelberg, 1999, pp. 327-376.

[16] B. Smit, T. L. M. Maesen, Nature 2008, 451, 671-678.

[17] W. O. Haag, R. M. Dessau, Berlin, 1984, pp. 305-316.

[18] S. Kotrel, H. Knözinger, B. C. Gates, Micro. Meso. Mater. 2000, 35-36, 11-20.

[19] H. Konno, T. Okamura, T. Kawahara, Y. Nakasaka, T. Tago, T. Masuda, Chem. Eng. J. 2012, 207-208, 490-496.

[20] P. Voogd, H. Van Bekkum, Appl. Catal. 1990, 59, 311-331.

[21] W. O. Haag, R. M. Lago, P. B. Weisz, Faraday Discuss. Chem. Soc. 1981, 72, $317-$ 330.

[22] A. Janda, A. T. Bell, J. Am. Chem. Soc. 2013, 135, 19193-19207.

[23] J. A. Swisher, N. Hansen, T. Maesen, F. J. Keil, B. Smit, A. T. Bell, J. Phys. Chem. C 2010, 114, 10229-10239.

[24] A. Janda, B. Vlaisavljevich, L.-C. Lin, S. M. Sharada, B. Smit, M. Head-Gordon, A. T. Bell, J. Phys. Chem. C 2015, 119, 10427-10438.

[25] B. Xu, C. Sievers, S. Hong, R. Prins, J. van Bokhoven, J. Catal. 2006, 244, 163-168.

[26] S. M. Babitz, B. A. Williams, J. T. Miller, R. Q. Snurr, W. O. Haag, H. H. Kung, Appl. Catal. A Gen. 1999, 179, 71-86.

[27] H. Li, S. A. Kadam, A. Vimont, R. F. Wormsbecher, A. Travert, ACS Catal. 2016, 6, 4536-4548.

[28] T. Jiang, F. Göltl, R. E. Bulo, P. Sautet, ACS Catal. 2014, 4, 2351-2358.

[29] T. Bučko, J. Hafner, J. Catal. 2015, 329, 32-48.

[30] F. Göltl, J. Hafner, Micro. Meso. Mater. 2013, 166, 176-184.

[31] J. Van der Mynsbrugge, A. Janda, S. Mallikarjun Sharada, L.-C. Lin, V. Van Speybroeck, M. Head-Gordon, A. T. Bell, ACS Catal. 2017, 2685-2697.

[32] A. Janda, B. Vlaisavljevich, B. Smit, L.-C. Lin, A. T. Bell, J. Phys. Chem. C 2017, $121,1618-1638$.

[33] H. van Koningsveld, J. C. Jansen, H. Van Bekkum, Zeolites 1990, 10, 235-242.

[34] N. H. Heo, C. W. Kim, H. J. Kwon, G. H. Kim, S. H. Kim, S. B. Hong, K. Seff, J. Phys. Chem. C 2009, 113, 19937-19956. 
[35] D. H. Olson, N. Khosrovani, A. W. Peters, B. H. Toby, J. Phys. Chem. B 2000, 104, 4844-4848.

[36] J. Dědeček, D. Kaucký, B. Wichterlová, Chem. Commun. 2001, 970-971.

[37] J. Dedecek, L. Capek, D. Kaucký, Z. Sobalík, B. Wichterlová, J. Catal. 2002, 211, 198-207.

[38] J. Dědeček, B. Wichterlová, J. Phys. Chem. B 1999, 103, 1462-1476.

[39] J. Dědeček, D. Kaucký, B. Wichterlová, Micro. Meso. Mater. 2000, 35-36, 483-494.

[40] J. Dědeček, J. Čejka, M. Oberlinger, S. Ernst, Stud. Surf. Sci. Catal. 2002, 142, 23-30.

[41] A. Bhan, A. D. Allian, G. J. Sunley, D. J. Law, E. Iglesia, J. Am. Chem. Soc. 2007, 129, 4919-4924.

[42] A. Vjunov, J. L. Fulton, T. Huthwelker, S. Pin, D. Mei, G. K. Schenter, N. Govind, D. M. Camaioni, J. Z. Hu, J. A. Lercher, J. Am. Chem. Soc. 2014, 136, 8296-8306.

[43] J. M. Thomas, J. Klinowski, Elsevier, 1985, pp. 199-374.

[44] M. Stöcker, Stud. Surf. Sci. Catal. 1994, 85, 429-507.

[45] Z. Gabelica, J. B. Nagy, P. Bodart, G. Debras, E. G. Derouane, P. A. Jacobs, in Zeolites: Science and Technology, Springer, Dordrecht, Dordrecht, 1984, pp. 193-210.

[46] S. Sklenak, J. Dědeček, C. Li, B. Wichterlová, V. Gábová, M. Sierka, J. Sauer, Phys. Chem. Chem. Phys. 2008, 11, 1237-1247.

[47] S. Sklenak, J. Dědeček, C. Li, B. Wichterlová, V. Gábová, M. Sierka, J. Sauer, B. Wichterlová, V. Gabova, Angew. Chem. Int. Ed. 2007, 46, 7286-7289.

[48] J. Dědeček, V. Balgová, V. Pashkova, P. Klein, B. Wichterlová, Chem. Mater. 2012, 24, 3231-3239.

[49] E. G. Derouane, J. C. Védrine, R. R. Pinto, P. M. Borges, L. Costa, M. A. N. D. A. Lemos, F. Lemos, F. R. Ribeiro, Catal. Rev. 2013, 55, 454-515.

[50] J. Dědeček, Z. Sobalík, B. Wichterlová, Catal. Rev. 2012, 54, 135-223.

[51] S. M. Sharada, P. M. Zimmerman, A. T. Bell, M. Head-Gordon, J. Phys. Chem. C 2013, 117, 12600-12611.

[52] D. H. Olson, W. O. Haag, R. M. Lago, J. Catal. 1980, 61, 390-396.

[53] W. O. Haag, in Zeolites and Related Microporous Materials: State of the Art 1994 Proceedings of the 10th International Zeolite Conference, Garmisch-Partenkirchen, Germany, 17-22 July 1994, Elsevier, 1994, pp. 1375-1394.

[54] W. O. Haag, R. M. Lago, P. B. Weisz, Nature 1984, 309, 589-591.

[55] T. F. Narbeshuber, H. Vinek, J. A. Lercher, J. A. Lercher, J. Catal. 1995, 157, 388395.

[56] F. Eder, J. A. Lercher, Zeolites 1997, 18, 75-81.

[57] A. Bhan, R. Gounder, J. Macht, E. Iglesia, J. Catal. 2008, 253, 221-224.

[58] F. Eder, M. Stockenhuber, J. A. Lercher, J. Phys. Chem. B 1997, 101, 5414-5419.

[59] B. A. De Moor, M.-F. Reyniers, O. C. Gobin, J. A. Lercher, G. B. Marin, J. Phys. Chem. C 2011, 115, 1204-1219.

[60] S. Kotrel, M. P. Rosynek, J. H. Lunsford, J. Phys. Chem. B 1999, 103, 818-824.

[61] S. M. Maier, A. Jentys, J. A. Lercher, J. Phys. Chem. C 2011, 115, 8005-8013.

[62] X. Zheng, P. Blowers, J. Phys. Chem. A 2005, 109, 10734-10741.

[63] X. Zheng, P. Blowers, J. Mol. Catal. A Chem. 2005, 229, 77-85.

[64] X. Zheng, P. Blowers, J. Phys. Chem. A 2006, 110, 2455-2460.

[65] B. J. Ding, S. P. Huang, W. C. Wang, Chin. J. Chem. 2008, 26, 1173-1180.

[66] M. Boronat, A. Corma, Catal. Lett. 2015, 145, 162-172. 
[67] E. Dempsey, J. Catal. 1974, 33, 497-499.

[68] E. Dempsey, J. Catal. 1975, 39, 155-157.

[69] D. Barthomeuf, Mater. Chem. Phys. 1987, 17, 49-71.

[70] E. L. First, C. E. Gounaris, J. Wei, C. A. Floudas, Phys. Chem. Chem. Phys. 2011, 13, 17339-17358.

[71] P. Hohenberg, W. Kohn, Phys. Rev. 1964, 136, B864.

[72] W. Kohn, L. J. Sham, Phys. Rev. 1965, 140, A1133-A1138.

[73] C. Tuma, J. Sauer, Phys. Chem. Chem. Phys. 2006, 8, 3955-3965.

[74] V. Van Speybroeck, K. De Wispelaere, J. Van der Mynsbrugge, M. Vandichel, K. Hemelsoet, M. Waroquier, Chem. Soc. Rev. 2014, 43, 7326-7357.

[75] J.-D. Chai, M. Head-Gordon, J. Chem. Phys. 2008, 128, 084106.

[76] J.-D. Chai, M. Head-Gordon, Phys. Chem. Chem. Phys. 2008, 10, 6615-6620.

[77] J. Gomes, P. M. Zimmerman, M. Head-Gordon, A. T. Bell, J. Phys. Chem. C 2012, 116, 15406-15414.

[78] E. A. Pidko, ACS Catal. 2017, 7, 4230-4234.

[79] A. T. Bell, M. Head-Gordon, Annu. Rev. Chem. Biomol. Eng. 2011, 2, 453-477.

[80] M. Waroquier, K. De Wispelaere, J. Hajek, S. Rogge, J. Van der Mynsbrugge, V. Van Speybroeck, in Nanotechnology in Catalysis, Wiley-VCH Verlag GmbH \& Co. KGaA, Weinheim, Germany, 2017, pp. 1055-1100.

[81] P. M. Zimmerman, M. Head-Gordon, A. T. Bell, J. Chem. Theory Comput. 2011, 7, 1695-1703.

[82] Y.-P. Li, J. Gomes, S. Mallikarjun Sharada, A. T. Bell, M. Head-Gordon, J. Phys. Chem. C 2015, 119, 1840-1850.

[83] S. Grimme, Chemistry 2012, 18, 9955-9964.

[84] Phys. Chem. Chem. Phys. 2009, 11, 2939-2958.

[85] B. A. De Moor, A. Ghysels, M.-F. Reyniers, V. Van Speybroeck, M. Waroquier, G. B. Marin, J. Chem. Theory Comput. 2011, 7, 1090-1101.

[86] A. Ghysels, D. Van Neck, M. Waroquier, J. Chem. Phys. 2007, 127, 164108.

[87] A. Ghysels, T. Verstraelen, K. Hemelsoet, M. Waroquier, V. Van Speybroeck, J. Chem. Inf. Model. 2010, 50, 1736-1750.

[88] G. Piccini, J. Sauer, J. Chem. Theory Comput. 2014, 10, 2479-2487.

[89] G. Piccini, M. Alessio, J. Sauer, Y. Zhi, Y. Liu, R. Kolvenbach, A. Jentys, J. A. Lercher, J. A. Lercher, J. Phys. Chem. C 2015, 119, 6128-6137.

[90] Y.-P. Li, A. T. Bell, M. Head-Gordon, J. Chem. Theory Comput. 2016, 12, 2861-2870.

[91] J. Hajek, J. Van der Mynsbrugge, K. De Wispelaere, P. Cnudde, L. Vanduyfhuys, M. Waroquier, V. Van Speybroeck, J. Catal. 2016, 340, 227-235.

[92] P. Cnudde, K. De Wispelaere, J. Van der Mynsbrugge, M. Waroquier, V. Van Speybroeck, J. Catal. 2017, 345, 53-69.

[93] P. M. Zimmerman, D. C. Tranca, J. Gomes, D. S. Lambrecht, M. Head-Gordon, A. T. Bell, J. Am. Chem. Soc. 2012, 134, 19468-19476.

[94] J. Gomes, M. Head-Gordon, A. T. Bell, J. Phys. Chem. C 2014, 118, 21409-21419.

[95] J. VandeVondele, M. Krack, F. Mohamed, M. Parrinello, T. Chassaing, J. Hutter, Comp. Phys. Commun. 2005, 167, 103-128.

[96] V. Van Speybroeck, K. Hemelsoet, L. Joos, M. Waroquier, R. G. Bell, C. R. A. Catlow, Chem. Soc. Rev. 2015, 44, 7044-7111.

[97] A. Laio, M. Parrinello, Proc. Nat. Acad. Sci. 2002, 99, 12562-12566. 
[98] P. Fleurat-Lessard, T. Ziegler, J. Chem. Phys. 2005, 123, 084101.

[99] L. Sutto, S. Marsili, F. L. Gervasio, Wiley Interdisciplinary Reviews: Computational Molecular Science 2012, 2, 771-779.

[100] P. A. Bash, U. C. Singh, R. Langridge, P. A. Kollman, Science 1987, 236, 564-568.

[101] E. Darve, A. Pohorille, J. Chem. Phys. 2001, 115, 9169-9183.

[102] C. Jarzynski, Phys. Rev. Lett. 1997, 78, 2690-2693.

[103] M. Iannuzzi, A. Laio, M. Parrinello, Phys. Rev. Lett. 2003, 90, 238302.

[104] B. Ensing, A. Laio, M. Parrinello, M. L. Klein, J. Phys. Chem. B 2005, 109, 66766687.

[105] A. Laio, A. Rodriguez-Fortea, F. L. Gervasio, J. Phys. Chem. B 2005, 109, 6714-6721.

[106] S. L. C. Moors, K. De Wispelaere, J. Van der Mynsbrugge, M. Waroquier, V. Van Speybroeck, ACS Catal. 2013, 3, 2556-2567.

[107] J. Van der Mynsbrugge, S. L. C. Moors, K. De Wispelaere, V. Van Speybroeck, ChemCatChem 2014, 6, 1906-1918.

[108] K. De Wispelaere, B. Ensing, A. Ghysels, E. J. Meijer, V. Van Speybroeck, Chem. Eur. J. 2015, 21, 9385-9396.

[109] L. Benco, T. Bučko, J. Hafner, J. Catal. 2011, 277, 104-116.

[110] P. G. Bolhuis, D. Chandler, C. Dellago, P. L. Geissler, Annu. Rev. Phys. Chem. 2002, 53, 291-318.

[111] C. Dellago, P. G. Bolhuis, P. L. Geissler, Adv. Chem. Phys. 2002, 123, 1-78.

[112] T. Bučko, L. Benco, O. Dubay, C. Dellago, J. Hafner, J. Chem. Phys. 2009, 131, 214508 . 